\author{
Apr/2019 \\ Working Paper 19-10 \\ rcea.org/RePEc/pdf/wp19-10.pdf
}

\title{
IT'S ALL IN THE STARS: THE CHINESE ZodiaC AND THE EFFECTS OF PARENTAL INVESTMENTS ON OFFSPRING'S COGNITIVE AND NONCOGNITIVE SKILl DEVELOPMENT
}

\author{
Chih Ming Tan \\ University of North Dakota, USA \\ RCEA
}

Xiao Wang

University of Science and Technology of China, China

\author{
Xiaobo Zhang \\ Peking University, China \\ International Food Policy Research Institute, USA
}

Copyright belongs to the author. Short sections of the text, not exceeding three paragraphs, can be used provided proper acknowledgement is given.

The Rimini Centre for Economic Analysis (RCEA) was established in March 2007. RCEA is a private, nonprofit organization dedicated to independent research in Applied and Theoretical Economics and related fields. RCEA organizes seminars and workshops, sponsors a general interest journal, the Review of Economic Analysis (REA), and organizes a biennial conference, the Rimini Conference in Economics and Finance (RCEF). Scientific work contributed by the RCEA Scholars is published in the RCEA Working Paper series.

The views expressed in this paper are those of the authors. No responsibility for them should be attributed to the Rimini Centre for Economic Analysis. 


\title{
It's All in the Stars: The Chinese Zodiac and the Effects of Parental Investments on Offspring's Cognitive and Noncognitive Skill Development ${ }^{\#}$
}

\author{
Chih Ming Tan, Xiao Wang, and Xiaobo Zhang*
}

January, 2019

\begin{abstract}
The importance of (early) parental investments in children's cognitive and noncognitive outcomes is a question of deep policy significance. However, because parental investments are arguably endogenous, empirically estimating their importance poses a challenge. This paper exploits a rich and novel dataset, the China Family Panel Studies, and proposes a culture-specific instrumental variable based on the Chinese zodiac, in order to identify the impact of parental investments. By looking at the outcomes of children born just before and just after the cutoff for a "lucky" (or “nonlucky”) zodiac sign, we find that parents' investments have significant effects on their offspring's development of both cognitive and noncognitive skills.
\end{abstract}

Keywords: Cognitive Skills; Noncognitive Skills; Parental Investments; Zodiac Signs; China

JEL Codes: I10; I15; J24; O12; O53

\footnotetext{
\# Tan thanks the Greg and Cindy Page Faculty Distribution Fund for financial support. We thank Xin Zhang, and all participants at conferences and seminars that provided us insightful comments and suggestions.

* Tan: Department of Economics, College of Business and Public Administration, University of North Dakota, Gamble Hall, 293 Centennial Drive, Grand Forks, ND 58202-8369, US. Tel: (701) 777-3349. chihming.tan@business.und.edu. Wang (corresponding author): International Institute of Finance, School of Management, University of Science and Technology of China, 96 Jinzhai Road, Hefei, Anhui, 230026, People’s Republic of China. iriswangx@gmail.com. Zhang: National School of Development, Peking University, Beijing 100871, China, and International Food Policy Research Institute, 1201 Eye St., NW, Washington, DC 20005, US. x.zhang@nsd.pku.edu.cn.
} 


\section{Introduction}

This paper contributes to an extensive literature about the impact of parental investments on children's cognitive and noncognitive skills development. Existing work suggests that the economic returns on cognitive and noncognitive skills are potentially large both for individual well-being (Heckman and Rubinstein 2001; Heckman, Stixrud, and Urzua 2006; Borghans et al. 2008; Chetty et al. 2011; Heckman, Pinto, and Savelyev 2013; Cadena and Keys 2015) and for economic growth (Hanushek and Dennis 2000; Hanushek and Woessmann 2008). Early investments by parents play an important role in shaping cognitive and noncognitive skills in their offspring. It has been postulated that early life investments generate higher returns than investments made later in the child's life (Shonkoff and Phillips 2000; Carneiro and Heckman 2005; Kirchsteiger and Sebald 2010; Anger and Schnitzlein 2017).

A major challenge in the development and labor economics literature is to properly identify the economic returns on early childhood educational investments. A key complication faced by econometricians in estimating the returns on early parental investments is that such investments are endogenous. Parental investment decisions may respond to incentives based on their own private knowledge about their children, which are often not observable by the econometrician. For example, parents may know something about the relative level of innate motivation of their various children and may allocate scarce resources among their children to maximize the children's overall outcomes based on this knowledge. ${ }^{1}$ Most previous literature has followed a structural model, which delivers a set of structural equations tying initial conditions and the sequence of parental investments across multiple periods to the evolution

1 Heckman and Mosso (2014) explained how parents' decisions to either reinforce or compensate for a child's disadvantages rely critically on both the parents' preference for equality of outcomes across their children and the curvature of the human capital production function. 
of cognitive and noncognitive skills (Cunha and Heckman 2008; Cunha, Heckman, and Schennach 2010).

This paper employs a quasi-experimental approach, which does not need a fully specified model as the structural approach does. Moreover, using China Family Panel Studies (CFPS) data, the paper employs a particular culture-specific determinant of parental investment behavior as a source of exogenous variation to properly identify and consistently estimate the returns on early investments. Specifically, this analysis employs the child survey module in the 2010, 2012, and 2014 waves of the CFPS for our analysis. The CFPS is novel in that it includes direct measures of both cognitive (word recognition and mathematical ability) and noncognitive (curiosity, organization, optimism, mistake tolerance, and anger control) skills for children.

This paper proposes a set of instrumental variables (IVs) for parental investments that is specific to Chinese/Asian culture. ${ }^{2}$ There are 12 lunar zodiac signs-Rat, Ox, Tiger, Rabbit, Dragon, Snake, Horse, Sheep, Monkey, Rooster, Dog, and Pig-and it is well known that some parents plan the birth of their children to coincide with the "lucky" signs. For example, because positive characteristics are associated with the Dragon zodiac sign, some parents plan their children's birth to fall in the year of the Dragon (Lim 2012). This phenomenon exists even among Asian immigrants to the United States (Johnson and Nye 2011). Based on established beliefs in Chinese culture, we categorize the zodiac signs into (1) "lucky" signs: Tiger and Dragon, (2) “unlucky” signs: Snake and Sheep, and (3) “neutral” signs: all others.

${ }^{2}$ Lunar zodiac signs (as opposed to the solar signs common in Western cultures) originated in China and spread to other Asian countries. But there are minor differences in practices across those countries. For example, in Vietnam, zodiac signs are combined with the five essential elements (Do and Phung 2010). People in China generally know and care only about the zodiac signs, not their interactions with other astrological constructs. 
How can zodiac signs have an impact on parental investments? ${ }^{3}$ There are two channels for such an effect. The first is the channel of superstition, a purely cultural mechanism that is specific to the Asian (Chinese, in this case) context, whereby parents possess strong beliefs about children born under lucky signs. Their belief then drives their decisions about investment in their children. A parent may decide, for example, "My child is a Dragon and is likely to be successful; I should invest in my child.”

The second way in which a child's sign can influence parental investments is the rational channel. Through this channel, even if parents do not themselves believe in the superstitious powers of the zodiac, they may still be incentivized to alter their investment behavior depending on their children's sign if they believe that there are sufficient superstitious parents in the population. This response is due to social interaction effects (Durlauf and Ioannides 2010; Blume et al. 2011), whereby the actions of some parents (in this case, the rational ones) are dependent upon the optimal choices of other (superstitious) parents. For example, the parents of children born under a neutral or unlucky zodiac sign may realize that children born under lucky signs do not have a mysterious zodiac advantage over their own children. However, they may also understand that the parents of their children's lucky sign counterparts believe that they do (and therefore increase their investments). In order to compete with them for educational opportunities, jobs, mates, and so on, the parents of the children with unlucky signs may therefore be incentivized to invest in their children to

3 Other works in the literature have explored how zodiac-related factors affect economic outcomes, but establishing causality has been a serious issue. For example, Vere (2008) employed variations in fertility across different lunar years as an instrument to estimate the effect of fertility on female labor supply. Do and Phung (2010) and Johnson and Nye (2011) found that children born in the year of the Dragon have longer schooling in Vietnam and among Asian immigrants to the United States. In contrast, Wong and Yung (2005), using Hong Kong census data, found no evidence that children born in the year of the Dragon have better earnings outcomes. 
increase their chances of success if superstitious parents are also doing so. These two channels suggest the potential relevance of zodiac-related IVs in influencing parental investments.

However, the validity of the IV approach relies essentially on these zodiac signs being randomly assigned across children. If parents purposely choose their children's birth dates in favor of lucky zodiac signs, then selection bias arises when comparing children's outcomes. Therefore, we need to exclude the children born to parents who have intentionally planned for their children to be born under a lucky sign.

Our strategy for identifying such children is based on the assumption that parents who are intent on achieving a particular zodiac sign for their child would be very unlikely to plan for their child to be born close to the margins of the targeted lunar year. Instead they would plan their child's birth date somewhere in the middle of a lunar year (away from the margins of the preferred zodiac sign, where there would be a risk of the child's being born in the “wrong” year). We assume that the parents whose offspring is born within a small window around the end of one lunar year and the beginning of the next lunar year (that is, a window across two signs, one “desirable” and one "less desirable”) are not engaging in sign selection. Their child just happens to be born under one sign as opposed to the other, adjacent sign. Specifically, we define the signs of children born within such a window as "random zodiac signs," and we use this variable as an IV for parental investments. The proposed IV approach is therefore closely related to a regression discontinuity design approach. ${ }^{4}$

This paper further restricts comparisons between children from a pair of adjacent zodiac signs who are in the same schooling cohort and thus would be facing the same market, with the same degree of competition, for jobs and educational opportunities. We assume that

${ }^{4}$ Our work is related to Zhang et al. (2014) who employed a different identification strategy; i.e., using dynamic panel methods to control for endogeneity, and a different measure of parental investment in children (parental absence). They found that parental absence reduced children's cognitive achievements in rural China. 
children born under lucky signs and those born under adjacent neutral or unlucky signs (together, the "nonlucky" signs) are otherwise exchangeable in terms of their unobserved characteristics. This approach is important because we are not able to control for parental expectations regarding the future condition of such markets and opportunities for their children across the birth cohorts in the sample. The random assignment of zodiac signs across children born within the window between two lunar years thus provides a source of exogenous variation in culturally induced differences in parental investments, allowing us to identify the effects of these investments on children's cognitive and noncognitive outcomes.

We first find supporting evidence for our hypotheses on the instrumental variables. In the first stage, we find that (i) parents invest differently between children with lucky (unlucky) random zodiac signs and children with adjacent other random zodiac signs, and (ii) parents invest indifferently between children with adjacent neutral random zodiac signs. In the second stage of IV regression, we find that (i) a 10\% increase in total education costs can improve the word recognition test score by 0.718 (9.6\% of its standard deviation) and math test score by 0.374 (8.9\% of its standard deviation); (ii) a 10\% increase in total education costs can improve the assessment scores for children's curiosity, organizational skills, the ability to cope with or tolerate others' mistakes, and the ability to control anger or anxiety between 0.015 (1.9\% of its standard deviation) and 0.054 (5.8\% of its standard deviation). We then conduct a variety of robustness checks on the treatment, the definition of random zodiac signs, an alternative explanation of the benchmark results, and birth date measurement error, and find that all robustness checks are consistent with the benchmark results.

In terms of its broader contribution, this paper is related to an emerging literature that employs exogenous shocks to initial endowments to investigate the effects of early investments on children's cognitive and noncognitive outcomes. Tan, Tan, and Zhang (2015), 
for example, examined the impact of in utero famine exposure on later-life cognitive outcomes in the context of the Great Chinese Famine of 1959-1961. Leight, Glewwe, and Park (2015) exploited early rainfall shocks to investigate the evolution of children's cognitive and noncognitive skills, finding evidence that parents invest to reduce the impact of negative shocks. The literature that employs policy experiments to elicit the impact of childhood investment includes Adhvaryu and Nyshadham (2016, pre-birth exposure to iodine), Ludwig and Miller (2007, discontinuity in Head Start funding), and Chetty et al. (2011, random assignment of teachers and students to classrooms).

This paper also contributes to the growing literature on human capital development under diverse cultural backgrounds, especially on whether cultural superstition can induce parents' investment. Our finding is largely consistent with Mocan and Yu (2017). One key difference is that our paper employs a regression discontinuity design approach to identify the effect of random assignment of zodiac signs on parents' investment. Lastly, this paper provides a culture-specific case study on how the aspiration of parents from their children's random zodiac signs stimulates investment and helps children develop their skills, stemming from the role of hope in the development literature (Sen, 1999; Beaman et al., 2002) and from the role of parental belief on their investment (Boneva and Rauh, 2018).

The rest of the paper is organized as follows. Section 2 describes the data and the details of the methodology. Section 3 discusses the findings, and Section 4 concludes.

\section{Data and Methodology}

Data

Our main dataset is from the CFPS surveys conducted in 2010, 2012, and 2014. The CFPS is “a nationally representative, annual longitudinal survey of Chinese communities, 
families, and individuals," funded by the Chinese government and conducted by the Institute of Social Science Survey of Peking University, China. The CFPS was formally launched in 2010. All individuals in families surveyed in 2010 are followed up in every subsequent survey, which takes place every two years. The CFPS includes four questionnaires: community, family, adult, and child. Our data are constructed using the child questionnaires for 2010, 2012, and 2014, complemented by the corresponding adult and family survey questionnaires. Because the CFPS provides a unique identification number for each individual, we are able to combine information from the three surveys. The CFPS also has the advantage of providing direct measures of children's cognitive and noncognitive skills, parents' investments, and family background information.

The child survey in each year includes all children with age 15 and below from 2010 core households and children with the same age range from the new households added in that year. In the child survey, parents answer all questions for children with age below 10. For children with age 10 and above, both parents and children answer questionnaires. Each child in a household has one questionnaire in the survey.

CFPS enumerators mainly conduct face-to-face interviews. For example, the ratio of face-to-face interview in CFPS 2014 child survey is 93.68\%. They also conduct interviews by phone if interviewees physically stay in another residence rather than their registered one. All interviews are recorded for cross-checking. If the interviews are interrupted by unpredictable factors, enumerators complement the initially unfinished questions with a second interview. Overall, the work by CFPS data collectors guarantees the completeness and accurateness of survey information.

\section{Defining Key Variables}


Cognitive skills. The CFPS 2010 survey includes word recognition and math tests as measures of cognitive skills. The word recognition and math tests have 34 and 24 questions, respectively, ordered from the easiest to the most difficult. The starting point from which a respondent answers questions depends on his or her education level. The ultimate test score is the number (rank) of the most difficult question that the respondent is able to answer correctly. If a respondent fails to correctly answer any question among those for his or her education group, the score is the lowest for that education level minus 1. For example, in the word recognition test, children with 7 to 9 years of education start at the 9th question. If the most difficult question a child answers correctly is the 11th, his or her test score is 11 . If the child starts at question 9 but fails to answer questions 9, 10, and 11 correctly, his or her score is 8 .

CFPS 2012 survey does not have word recognition and math tests. CFPS 2014 survey generally follows the word recognition and math tests in CFPS 2010 but adjusts the setup of the starting point for respondents. It allows the respondents with a high starting point to re-start with a lower one if they answer three consecutive questions incorrectly. Nonetheless, CFPS 2014 survey also computes the scores for respondents assuming the fixed starting point, in order to make scores comparable with 2010 tests. We use the comparable scores in 2014 CFPS.

Noncognitive skills. The CFPS also includes questions regarding noncognitive skills for children in 2010, 2012, and 2014 surveys. We derive five measures corresponding to the "big five” noncognitive skills: openness to experience, conscientiousness, extroversion, agreeableness, and neuroticism versus emotional stability (OCEAN). The proxy variables for OCEAN are the survey questions that ask parents, respectively, whether the child is curious, whether the child is organized, whether the child is optimistic, whether the child can tolerate others' mistakes, and whether the child can control his or her anger. These five noncognitive 
skill variables, based on parents' survey answers, take values of 1 for "strongly disagree," 2 for “disagree,” 3 for “neutral,” 4 for “agree,” or 5 for “strongly agree.”

Parental investments. We measure parental investments as total education

expenditures for the child in the previous year. ${ }^{5}$ These expenditures are deflated to thousands of 2010 Chinese renminbi (that is, to real values).

Children's and parents' characteristics. Using demographic and household information from the CFPS, we can control for a set of family characteristics including the child's gender, whether the family lives in a city, the number of siblings for the child, the father's and mother's age and education, and family income (in thousands of 2010 renminbi).

\section{Random Zodiac Signs}

The identifying assumption. We identify random zodiac signs for certain children based on their birth dates, which are available for children born between 1997 and 2010 in CFPS surveys 2010 to 2014. There are 12 zodiac signs in Chinese culture: Rat, Ox, Tiger, Rabbit, Dragon, Snake, Horse, Sheep, Money, Rooster, Dog, and Pig. A new zodiac sign starts on each Lunar New Year and continues throughout the lunar year. These zodiac signs constitute a repeating 12-year cycle. We categorize these 12 signs into three groups: the Tiger and Dragon are lucky signs, the Snake and Sheep are unlucky signs, and the others are neutral signs. The literature so far has focused on parents' investment in children born in the year of the Dragon (Veer, 2008; Wong and Yung, 2005). Moreover, news reports suggest that people influenced by the zodiac culture carefully plan their children's birth dates fall into the year of the Tiger

\footnotetext{
${ }^{5}$ Parental investments are measured per child in the survey.
} 
(Cima, 2015) ${ }^{6}$, or not into the year of the Snake or the Sheep (Wang, 2014; Wan, 2014; Lu and Hunt, 2015).

To rule out parents who select into the zodiac sign of their child, we define a child's zodiac sign as randomly assigned only if his or her birth date falls within the first two or last two months of the $\operatorname{sign}^{7}$, as illustrated in Figure 1. Therefore, we keep in the sample only children who were born within the first two or last two months of each lunar year, treating these children's zodiac signs as if they were randomly assigned.

Before formally defining the random zodiac signs, we provide some supporting evidence for our key identifying assumption that parents plan their children's birth dates to fall within the middle portions (i.e., away from the boundaries) of lucky zodiac years. This assumption implies that children's birth dates are more likely to fall into the middle months of a lucky zodiac year in comparison with other years. By the same logic, parents plan their children's birth dates not to fall in unlucky zodiac years. Consequently, children's birth dates are less likely to fall into the middle months of an unlucky zodiac year. We check the validity of the assumption using the 2005 mini-census survey by National Bureau of Statistics of China, which has the most complete coverage of people’s birth years and months.

The 2005 mini-census survey covers 2.5 million people born between 1895 and 2005 . We select two sub-samples that include the most recent three zodiac cycles (from 1972, the year of the Rat, to 2005, the most recent year) and the most recent five zodiac cycles (from 1948, the year of the Rat, to 2005) respectively. We cannot use the entire sample of people’s birth dates because the survival bias becomes severe among elderly people.

${ }^{6}$ People influenced mainly by the culture in Mainland China and Hong Kong view Tiger as a lucky zodiac, but not People in Taiwan.

${ }^{7}$ We normalize two months as sixty days in our definition, in order to avoid any inconsistency in the window length arisen from the number of days of a month. Results are consistent if we define the window length using the actual months. 
We define the birth ratio in the middle months of a lunar year as the percentage of people born in those months. In Table A.1, Panel A, we test the hypothesis that the birth ratios in the middle months of lucky zodiac years are not different with those for other lunar years. We can reject this hypothesis for both Tiger and Dragon. Take Dragon as an example, the birth ratio in the middle eight months of the Dragon years in the recent three zodiac cycles (1976, 1988, and 2000) is 0.697 , significantly higher than 0.675 , the birth ratio in the middle eight months of other lunar years. The birth ratio difference between the Dragon and other years is of economic significance, given the population size in China. Using 2000, one Dragon year as an example, it implies that in China, approximately 391,000 more children were born in the middle eight months in comparison with other years. ${ }^{8}$ As a robustness check, we also compare the birth ratios in the middle ten months of the Dragon years versus other years, which are 0.868 versus 0.836 , and the difference is statistically significant at the $1 \%$ level. Additionally, the differences in the birth ratio between Tiger and other zodiac signs are also statistically significant in the most recent three and five zodiac cycles, no matter whether the interval is eight or ten months.

In Table A.1, Panel B, we successfully verify that the birth ratios in the middle months of unlucky zodiac years are statistically smaller than those in other years in most cases. In the most recent three zodiac cycles, the birth ratios in the middle eight months of the Snake years $(1977,1989$, and 2001$)$ versus other years are 0.673 versus 0.677 , with the difference being significant at the $5 \%$ level. But if the middle months are measured as ten, the difference in the birth ratio between Snake and other zodiac signs becomes statistically insignificant. In the recent five zodiac cycles, the birth ratios in the middle eight months between Snake and

8 China's population in 2000 was 1,267,430,000. Given the birth rate in 2000 was 0.01403, $1,267,430,000 * 0.01403 *(0.697-0.675)=391,000$. Data resource: Bureau of National Statistics of China. 
others are 0.673 versus 0.676 , and in the middle ten months 0.841 versus 0.841 . Yet the difference in the middle-ten-month birth ratio between Snake and other zodiac signs is not significant. By comparison, the birth ratio in the middle months for the years of Sheep is significantly smaller than that in other years in all tests no matter whether we use eight or ten months to measure the middle months.

In summary, our exploration of the 2005 mini-census survey, the most complete coverage of birth dates of people that are influenced by the Chinese culture, verifies our identifying assumption that parents do plan their children's birth time according to the lucky (unlucky) zodiac signs. Therefore, children born within a (small) window across two zodiac signs are credibly "randomly” assigned with their zodiac signs.

Defining random zodiac signs. We are now ready to define the random zodiac signs. Due to the data availability of children's birth dates, cognitive skills, and noncognitive skills, we define 12 pairs of late/early “random” zodiac signs as the last/first two months of a lunar year. Take children born in 1997 as an example: The Lunar New Year was on February 7th. Children born between January $1^{\text {st }}$ and February 6th are "late Rat"9 and children born between February $7^{\text {th }}$ and April $7^{\text {th }}$ are “early Ox," as shown in Figure 2. Similarly, using this nomenclature, the remaining 11 pairs of random zodiac signs are late Ox versus early Tiger (1998), late Tiger versus early Rabbit (1999), late Rabbit versus early Dragon (2000), late Dragon versus early Snake (2001), late Snake versus early Horse (2002), late Horse versus early Sheep (2003), late Sheep versus early Monkey (2004), late Monkey versus early Rooster (2005), late Rooster versus early Dog 2 (2006), late Dog 2 versus early Pig 2 (2007), and late

\footnotetext{
${ }^{9}$ We do not have birth date data for children born in 1996 and consequently the late Rat includes children born from January 1, 1997, not earlier. In definitions of other late random zodiac signs, we include two months whenever data are available.
} 
Rat 2 versus early Ox 2 (2009). ${ }^{10}$ Children born in 2010 have noncognitive skill measures only and are used as the reference group in the regression for noncognitive skills. We do not define random zodiac signs for those children.

We note two additional points regarding our definition of random zodiac signs. First, Chinese zodiac signs depend on the lunar year, not the month, of birth. We can identify and isolate the impact of zodiac signs on parental investments by controlling for the effect of birth months that have potential influence on children's skills, such as duration of exposure to sunshine. Second, because of the window of months around which our random zodiac is defined, all children in this sample were born from December through April. Because the cutoff birth date in China for primary school entrance is September 1, the children within each pair of late and early zodiac signs are in the same grade. Hence, we automatically control for all schooling cohort fixed effects.

Details regarding the definitions of the above five groups of variables are in Appendix Table A.2, Panel A.

Summary Statistics of the Sample within the "Window"

Panels B and C of Table A.2 display respectively the summary statistics for the two window samples: children for whom the dataset contains measures of cognitive skills and children for whom it contains measures of noncognitive skills. There are 1,098 and 1,257 observations for cognitive skills (Panel B) and noncognitive skills (Panel C).

In the sample for cognitive skills, the average scores on the word recognition and math tests are approximately 21.3 and 10.4, respectively. On average, parents spent 2,051 renminbi (RMB) on each child's education over the previous year, and the average family income is

${ }^{10}$ There are no cognitive or noncognitive skill measures for children born in 2008. 
RMB 31,263; in other words, a representative family spent approximately 6.6 percent of its income on each child's education. 51.7 percent of children are male and 38.7 percent of children live in an urban area. A typical child's father is 41.0 years old and has 7.3 years of education, whereas his or her mother is 39.1 years old with 5.9 years of education.

In the sample for noncognitive skills, average scores on the five survey questions for noncognitive skills_curiosity, organization, optimism, mistake tolerance, and anger control-are 3.8, 3.5, 3.9, 3.6, and 3.4, respectively. These values indicate that parents, on average, evaluate their child’s noncognitive skills to be between “neutral” (3) and “agree” (4) for these questions. Approximately 54.3 percent of children are male and 34.4 percent of children live in an urban area. Because children for whom we have measures of noncognitive skills are younger than those with measures of cognitive skills, their parents are also younger.

We further depict a preliminary comparison in parental investments between lucky (unlucky) and their neighboring random zodiac signs, in order to show that random lucky (unlucky) signs induce parents to invest differently with those their children are born in the neighboring sign windows. Figures 3 and 4 present the comparison. We observe that parents on average invest more (less) on children with random lucky (unlucky) zodiac signs. Parents may invest more (less) on children with random lucky (unlucky) signs simply because they believe that their children are more (less) likely to succeed. This is the superstition channel. Another channel is social interactions, i.e., parents make investment decision on their children in response to what other parents have done. Even though we cannot separate the two channels in this paper, we do find that parents with children of lucky (unlucky) signs invest differently from those parents whose children are born with neighboring signs. The induced different parental investments generate exogenous variations and enable us to examine the effect of parental investments children's cognitive and non-cognitive skills. 


\section{Methodology}

We estimate the impact of parental investments on children's cognitive and noncognitive skills using a two-stage model, whereby parental investments are instrumented by the random zodiac signs. Specifically, the first-stage regression takes the following specification:

$$
\operatorname{pinv}_{i}=c+\operatorname{rzodiac}_{i} \delta+X_{i} \Gamma+v_{i}
$$

where $\operatorname{pinv}_{i}$ is the investments by the parents of child $i$; $c$ is a constant; rzodiac $_{\boldsymbol{i}}$ is child $i$ 's $1 \times k$ random zodiac sign vector; $\boldsymbol{\delta}$ is a $k \times 1$ coefficient vector; $\boldsymbol{X}_{\boldsymbol{i}}$ is a $1 \times m$ vector of control variables that include the child's age and gender, the number of siblings, the father's and mother's age and educational attainment, family income, the urban dummy (to control for location fixed effects), and the survey year dummies; $\quad \boldsymbol{\Gamma}$ is a $m \times 1$ coefficient vector; $v_{i}$ is the residual.

The IVs are the random zodiac signs discussed above. Our identification strategy therefore invokes the regression discontinuity design approach in that we make comparisons between individuals born within the boundaries of lucky and neutral/unlucky zodiac signs. That is, we think of the exact occurrence of a particular zodiac sign as being akin to an arbitrary policy rule. When forming the treatment and control groups, we consider observations within the neighborhood of the policy threshold to be randomly assigned.

The second-stage regression is given by

$$
\text { skill }_{i}=\alpha+\beta \widehat{\operatorname{lnv}}_{\imath}+X_{i} \Theta+\varepsilon_{i}
$$


where the dependent variable, skill, is a measure of the cognitive or noncognitive skills of child $i ; \alpha$ is a constant; $\widehat{\operatorname{plnv}_{l}}$ is the fitted parental investment from the first stage and $\beta$ is its coefficient; $\boldsymbol{\Theta}$ is the $m \times 1$ coefficient vector for the control variables in the second stage; $\boldsymbol{\varepsilon}_{\boldsymbol{i}}$ is the residual. Standard errors are clustered at the level of the birth year and month. In addition to our benchmark specifications, we also conduct a series of robustness exercises that we discuss below.

\section{Findings}

\subsection{Simple Ordinary Least Squares Results}

Before we present the estimation results for equations (1) and (2), we show simple ordinary least squares (OLS) regression results. Specifically, we regress children’s cognitive or noncognitive skills on parental investments, after controlling for the children's gender, the number of siblings, residence location, father's and mother's age and education, family income, children's birth year-month dummies, and the survey year dummies. Parental investments and family income are logged. ${ }^{11}$ In Panel A of Table 1 we find that parental investments (as measured by education costs in the previous year) have statistically significant impacts on children's word recognition and math test scores. In Panel B, we show that parental investments are positively correlated with a child's level of optimism and mistake endurance. These OLS results indicate that parental investments are positively associated with both the child's cognitive and noncognitive skills. However, these preliminary results do not account for the potential endogeneity of parents' investments.

\subsection{Benchmark Findings for Cognitive Skills}

${ }^{11}$ To avoid the missing observation problem caused by the value of zero, we use log $(1+$ parental investment) and log (1+family income). 
We next estimate a standard two-stage least squares regression, as described by equations (1) and (2). The control variables include children's gender, the number of siblings, the urban dummy, parents' age ${ }^{12}$ and education, logged family real income, and the survey year dummies. Note that random zodiac sign dummies already contain information on children's age. For example, in the sample for cognitive skills that includes children born between 1997 and 2004, if a child was defined as a late Rat, we know that the child was born in 1997 and was 13 years old during the 2010 survey.

Table 2 displays the first-stage regression for children whose cognitive skill scores are available. We run the regression of parental investments on random zodiac signs and other control covariates $^{13}$, setting children that were born in 2004 as the reference. The first-stage standard errors are clustered at the level of children's birth year and month. We also list the category (lucky, neutral, or unlucky) of each random zodiac sign. The Kleibergen-Paap Wald $F$ statistics show that the random zodiac signs are not weak instruments. The coefficients from late Rat (birth year: 1997) to early Sheep (birth year: 2003) become smaller gradually, reflecting the general pattern that parents invest more on elder children than younger children. ${ }^{14}$ We also observe that coefficients of lucky (unlucky) zodiac signs are different

${ }^{12}$ Alternatively, we have used parents' zodiac signs that are defined by parents' birth dates, in order to control for the possible parents' selection of children's zodiac signs due to the cultural superstition on the zodiac match between parents and children. Results are qualitatively and quantitatively consistent.

${ }^{13}$ We have considered the interaction between lucky (unlucky) zodiac signs and children's gender, as there are superstitions that Tiger girls or Sheep girls may have a different fate with their male counterparts. However, we do not find statistically significant differences between males and females and thus do not include the interaction in the benchmark results.

14 The only exceptions are coefficients for late Tiger and early Rabbit (birth year: 1999), which are larger than coefficients for elder children. The exception may be caused by the fact that late Tiger and early Rabbit children are at the age of taking the entrance exam of middle school in 2010 survey and consequently their parents invest more to help them prepare for the exam. 
from those of neighboring signs, consistent with the comparisons in Figures 3 and 4. Next we formally examine the coefficient differences.

In Table 2, we exploit three F-tests to check whether parents invest to different degrees in children with lucky vs. unlucky random zodiac signs. The null hypothesis of the first $F$-test is that the coefficients on lucky random zodiac signs are not different from those on other zodiac signs. Note that we need to compare the coefficients on lucky random zodiac signs with those on the neighboring random zodiac signs, based on our assumption that the relatively random determination of children's birth date around the Lunar New Year may induce parents to invest in children differently. As children with cognitive skill tests scores were born between 1997 and 2004, there are two lucky zodiac signs within the time range: Tiger (early Tiger in 1998, late Tiger in 1999) and Dragon (early Dragon in 2000, late Dragon in 2001). We conduct a joint test of "late Ox = early Tiger" (1998), "late Tiger = early Rabbit" (1999), “late Rabbit = early Dragon” (2000), and "late Dragon = early Snake” (2001). The F-test rejects the null hypothesis with a $p$-value of 0.01 .

The null hypothesis of the second F-test is that parents invest the same between children with random unlucky zodiac signs and children with other signs. Again, the joint test compares coefficients on two unlucky random zodiac signs-Snake and Sheep-and their neighboring random zodiac signs. The joint test is "late Dragon = early Snake" (2001), "late Snake = early Horse" (2002), and "late Horse = early Sheep" (2003). We can reject the null hypothesis with a p-value of 0.01 , implying that parents invest differently in children with unlucky random zodiac signs compared with children with other neighboring random zodiac signs.

Finally, we need to check if parents invest the same in children with neighboring neutral random zodiac signs to dismiss the concern that the first two F-tests above only reflect 
parents' different investments in children with different birth months rather than different types of random zodiac signs. The null hypothesis of the third F-test is a test of "late Rat = early Ox" (1997). As we cannot reject the null hypothesis of the third test, we are able to conclude that parents appear to be indifferent when investing in children with neutral random zodiac signs. This finding contrasts with the two previous F-tests that do reflect differentiated parental investments in children with lucky (unlucky) and other random zodiac signs.

Table 3 summarizes the second-stage results on how parental investments affect children's cognitive skills. Increased education expenditure significantly improves children’s word recognition and math test scores. The magnitude of the effect of parents' investments on cognitive skill development is quantitatively large. For example, a 10 percent increase in education expenditure raises a child's word recognition test score, on average, by 0.718 , or 9.6 percent of the standard deviation of this score (7.510). Similarly, a 10 percent increase in education expenditure raises the average math test score by 0.374 , or 8.9 percent of a standard deviation of this score (4.182).

\subsection{Benchmark Findings for Noncognitive Skills}

Next we examine the two-stage least squares regression results for noncognitive skills. The first-stage results are similar to those for cognitive skills in Table 2 and therefore we do not report those results to save space. The Kleibergen-Paap Wald F statistic in the first stage is 23.847, confirming that the random zodiac signs are not weak instruments.

In the second-stage regressions, displayed in Table 4, we find that for all pairs of random zodiac signs, parental investments (as measured by total education costs in the previous year) improve a child's curiosity, organization, tolerance of others' mistakes, and anger control, except that the coefficient of logged education cost is not significant in the 
regression for optimism. The magnitudes of the impacts are substantial and important. For example, a 10 percent increase in parents’ investment raises a child’s curiosity score by 0.015 , or 1.9 percent of the standard deviation (0.792). A 10 percent increase in parents' investment has an even larger effect on the score for being organized, 0.030 , or 3.4 percent of the standard deviation (0.882). Columns 4 through 5 of Table 4 show that a 10 percent increase in parents' investment can increase a child's scores on mistake tolerance and anger control, respectively, by 0.033 (3.9 percent of the standard deviation, 0.852) and 0.054 (5.8 percent of the standard deviation, 0.930).

Overall, the magnitude of the impact of parents' investment in children's noncognitive skills is smaller than that for children's cognitive skills. One reason may be that the type of parental investment we consider, measured by education expenditure such as books and tutoring classes, is simply more amenable to making a direct impact on children's cognitive skill improvement. In contrast, in order to improve children's noncognitive skills, parents may need to rely on other dimensions of investments (other aspects of parenting, perhaps) and not just education expenditure. CFPS does survey parents on their other types of parental investments, for example, asking parents with children 3-5 years old the frequency of reading books for children and the frequency of taking children out. However, the restricted children age range and the low respondence rate of parents generate too few observations that fall into the window of random zodiac signs, preventing us from checking the effects of those types of parental investments.

\subsection{Robustness Checks}

We now consider a range of robustness checks. The first check focuses on the treatment of the regression discontinuity design. The second check examines an alternative 
definition of random zodiac window, and the third check invalidates an alternative explanation from children's self-consciousness. The last check restricts the sample size to minimize the measurement error. ${ }^{15}$

The first robustness check examines whether it is the change in birth months, not the change in zodiac signs that has explanatory power for parental investment. We design a falsification test in which we shift the birth month window away from the Lunar New Year so that children's birth dates in each pair fall into the same lunar year. Specifically, we designate children born in the third and fourth months of each lunar year as the first group and children born in the fifth and sixth months as the second group. Note that children in these two groups of each lunar year have the same zodiac sign. Moreover, all these children were born before the cutoff date for primary school entry (September 1) and are consequently in the same schooling cohort.

In Table 5, we examine whether parents invest in differentiated ways across children in those groups. Consistent with the F-tests for random zodiac signs in Table 2, we need to check three hypotheses: whether parents invest indifferently on children in group 1 and group 2 with the lucky/unlucky/neutral zodiac signs. We expect the F-statistics cannot reject the null hypotheses, because there is no lucky-to-other or unlucky-to-other type shift between two neighboring groups. Take Column 1 in Table 5 as an example, the first $F$-test is a joint test for lucky zodiac signs: group 1 Tiger = group 2 Tiger (1998) and group 1 Dragon = group 2 Dragon (2000). The second F-test is a joint test for unlucky signs: group 1 Snake $=$ group 2 Snake (2001) and group 1 Sheep = group 2 Sheep (2003). The third $F$-test is a joint test for neutral signs: group 1 Ox = group 2 Ox (1997), group 1 Rabbit = group 2

${ }^{15}$ We have conducted one more robustness check: Exclude the first and the last weeks in each lunar year in the random zodiac sign window, in order to delete the possibility that parents may choose the child's zodiac sign through induced early or late delivery. The results are almost identical to the benchmark and therefore we do not report in detail to save space. 
Rabbit (1999), and group 1 Horse = group 2 Horse (2002). ${ }^{16}$ We cannot reject the null hypotheses for the three $F$-tests, suggesting that parents do not differentiate their investment in children if they have the same lucky/unlucky/neutral zodiac signs. In Column 2, Table 5, we employ three similar $F$-tests to check whether parents invest differently on children with lucky/unlucky/neutral zodiac signs; i.e., group 1 and group 2. Again we cannot reject the hypotheses for those three F-tests. Overall, the results confirm that it is the change in zodiac signs, not the change in birth months that explains differences in parents' investments.

The second robustness check uses an alternative asymmetric window period to designate the random zodiac signs. ${ }^{17}$ The asymmetric window period design is based on the medical fact that a baby can be delivered as early in the $28^{\text {th }}$ week of pregnancy with a relatively high survival rate, but can only be delivered as late as the $41^{\text {st }}$ to $42^{\text {nd }}$ week of pregnancy. ${ }^{18}$ We then design the random zodiac window as the first three months and the last month of a lunar year, in order to cover the unexpected early or late delivery. Take Dragon children as an example, given the medical fact, parents plan their children's birth between the fourth and eleventh month of the year of the Dragon, in order to avoid the extreme early delivery (three month earlier) or the extreme late delivery (one month later) that may make their children's zodiac into Rabbit (by early delivery) or Snake (by late delivery). In Table 6, we designate as random the zodiac signs of children born in the first three months or last month of the lunar year, and then repeat the two-stage least squares regressions for cognitive and noncognitive skills, as in the benchmark cases. The new results are both qualitatively and quantitatively consistent with the benchmark results.

${ }^{16}$ Children born in 2004 are used as the reference group in the regression for cognitive skills. Thus we do not test group 1 Monkey = group 2 Monkey (2004).

${ }^{17}$ We thank Octasiano M. Valerio Mendoza for suggesting this robustness check.

${ }^{18}$ https://www.mayoclinic.org 
In the third robustness check, we want to investigate whether the outcomes from zodiac signs are somehow a result of the child's innate self-consciousness of her zodiac sign rather than because of her interactions with her parents. We cannot directly control for children's self-consciousness about their zodiac signs because the CFPS does not have survey questions on it. The first approach we take is to limit the sample to the set of younger children; specifically, the sample of children no more than twelve years old when taking the survey. ${ }^{19}$ The assumption is that younger children are strongly shaped in their worldviews by their parents, and therefore have a purer response to parental investments, whereas older children may "grow into" their identity and "self-consciousness", taking into account a broader range of extraneous influences. In Table 7, we find that the benchmark results hold qualitatively. Interestingly we find that parents' investments have quantitatively smaller effect on young children’s cognitive skills but quantitatively larger effect on their noncognitive skills.

The second approach we take is to note that even though there is no survey question about children's self-consciousness, CFPS provides a number of measures on children's self-confidence that is closely related with children's self-consciousness. Those questions are "I feel that I am on an equal plane with others” (Equal), "I feel that I have a number of good qualities” (Quality), “I am able to do things as well as most other people” (Do well), "I take a positive attitude toward myself” (Positive), "I am satisfied with myself” (Satisfy), "I wish I could have more respect for myself” (Respect), and "I am in control of whatever happens to me” (Control). All seven variables take values of 1 for “strongly disagree,” 2 for “disagree,” 3 for “neutral,” 4 for “agree,” or 5 for “strongly agree.”

A potential concern is that children with random lucky zodiac signs have more innate confidence in themselves by virtue of their birth sign, and it is this self-confidence that affects

${ }^{19}$ Children that have word recognition and math tests were between ten and fifteen years old. Therefore, twelve is a reasonable cutoff age for the robustness check. 
children's cognitive and noncognitive skills, not parents' investments induced by random zodiac signs. In order to address this concern, we control for all seven self-confidence variables in the second stage of the benchmark regressions for the cognitive skill tests, and report results in Table 8 . All results are qualitatively consistent with the benchmark results. Moreover, the results show that self-confidence has no effect on children's cognitive skills. Because only 15 percent of children answered the self-confidence questions in the population data, the observations for that exercise (reported in Table 8) went down to 430. Furthermore, only 55 observations in the sample of noncognitive skills have non-missing values of self-confidence and consequently we could not perform the robustness check for children's noncognitive skills. Nevertheless, our findings do suggest that it is parental investments as opposed to any innate response of children to their birth signs that are responsible for our benchmark findings.

The fourth check verifies that our results are robust to possible “man-made” birth dates. Huang, Lei, and Zhao (2016) find that parents may manipulate children's birth dates under pressure from the one child policy. For example, parents may change the birth dates of their two children into the same day on their birth certificate, in order to create a "man-made" twin and avoid fines of having children beyond quota. In such a scenario, children's birth dates may not be accurate. To prevent our results from possible contamination by the manipulated birth dates, we restrict to children that are the only child in their family. Table 9 reports the results. Only 429 and 519 children that satisfy the criteria are in the samples for cognitive skill and noncognitive skill regressions respectively. In Panel A, parental investment induced by children's random zodiac signs exerts positive influence on children's cognitive skill measures, consistent with the benchmark results. In Panel B, parental investment has positive effects on children's organization, mistake tolerance, and anger control, while its effects on 
children's curiosity and organization are not statistically significant. Overall, due to the reduced sample size, parental investments have weaker positive effects on children's skills, qualitatively consistent with the benchmark results.

\section{Conclusion}

There is keen interest in the literature in properly identifying the potential impact of parental investments in education on children's cognitive and noncognitive development. A key challenge for consistently estimating this impact is the high likelihood that parental investments may be endogenous. That is, parents may make investment decisions in their children that are based on their own private information about their offspring, which is not observed by the researcher.

This paper proposes a culture-specific IV based on the Chinese zodiac as a source of exogenous variation for identifying the effects of parental investments on their offspring's skill formation. By defining a window around the boundary of a zodiac sign, and assuming that observations are randomly assigned across this boundary, we establish the exogeneity of the IV. Using the regression discontinuity approach to examine the outcomes of children born just before and just after the cutoff for a lucky versus nonlucky zodiac sign, we find that parental investments have significant effects on children's cognitive and noncognitive skill development. The main results confirm the findings in the literature, which are largely drawn from a structural approach. 
Figure 1: Lunar Years and Random Zodiac Signs

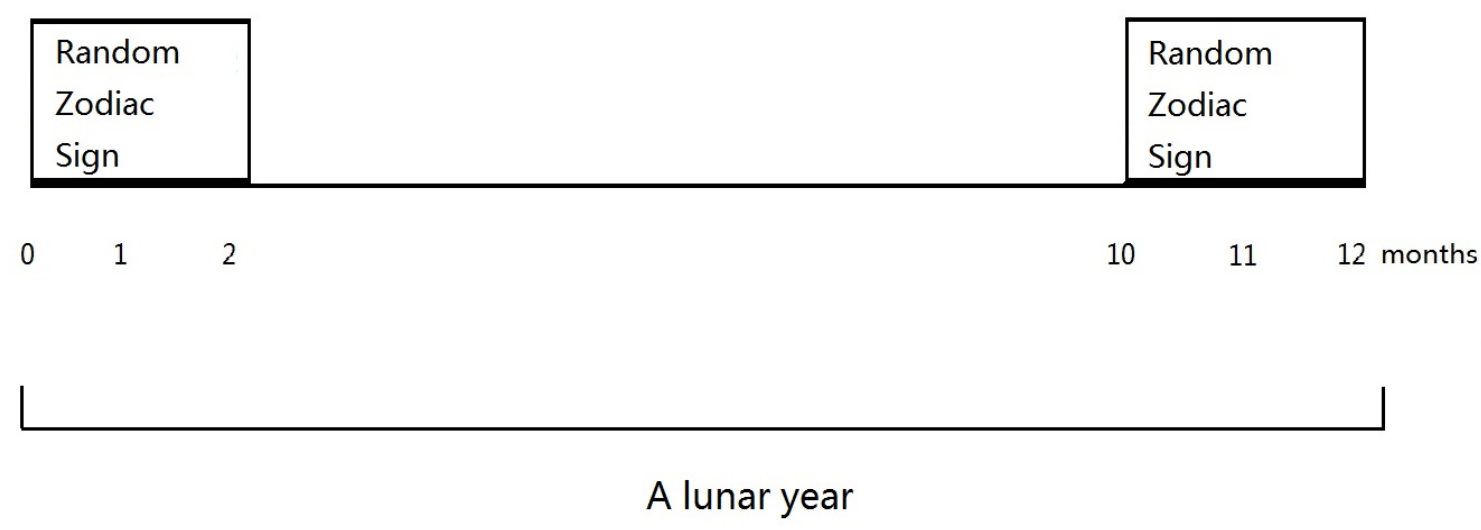


Figure 2: Late Rat and Early Ox in 1997

\begin{tabular}{|c|c|c|c|}
\hline 1ate Rat & early $0 x$ & & \\
\hline 01/01 & $02 / 07$ & $04 / 07$ & $12 / 31$ \\
\hline
\end{tabular}


Figure 3 Random zodiac signs and parental investment:

In the sample for cognitive skills
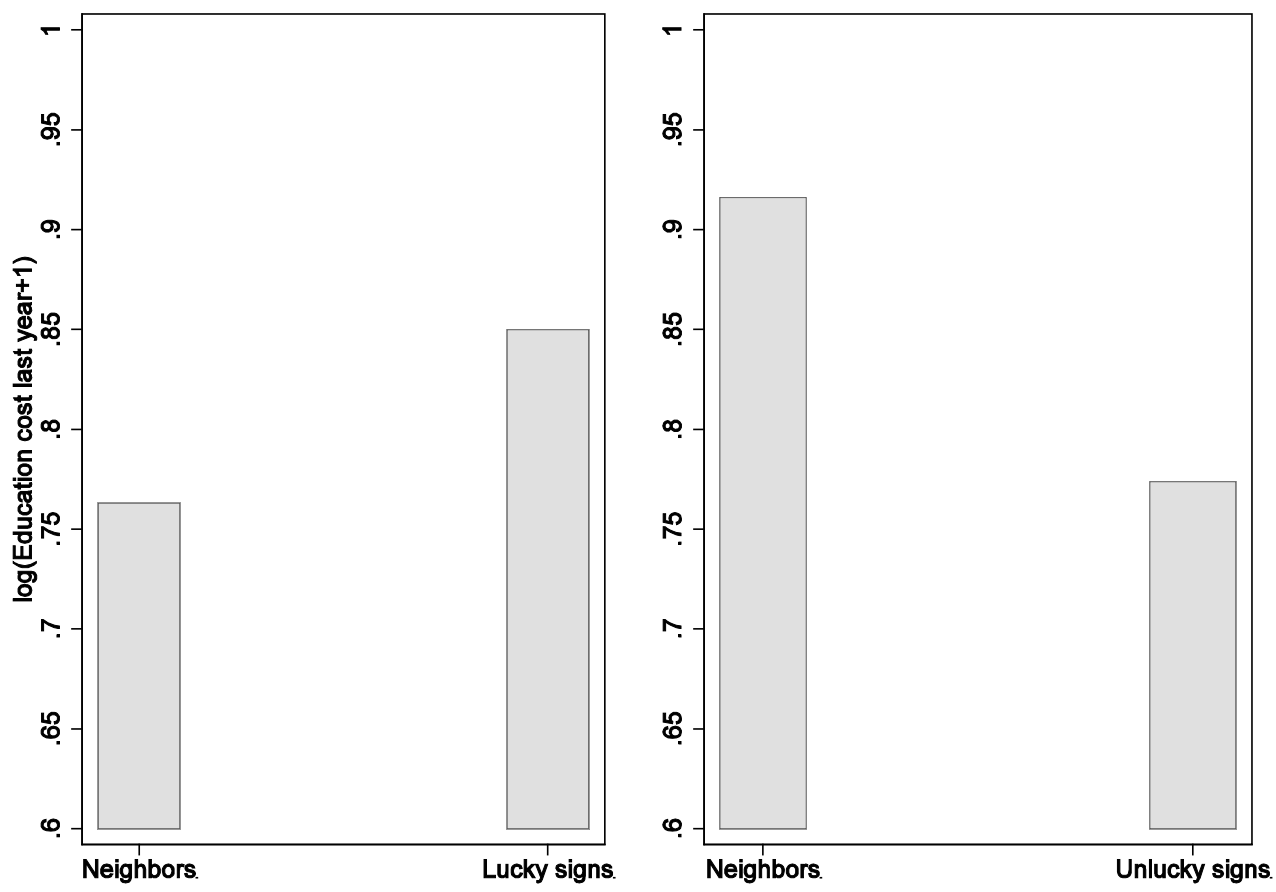

Note: This figure depicts the average parental investments measured as mean log (education cost last year +1 ) between lucky random zodiac signs and their neighboring signs, and between unlucky random zodiac signs and their neighboring signs, in the sample for cognitive skills. The lucky random zodiac signs include early Tiger (1998), late Tiger (1999), early Dragon (2000), and late Dragon (2001); their neighboring signs include late Ox (1998), early Rabbit (1999), late Rabbit (2000), and early Snake (2001). The unlucky signs are early Snake (2001), late Snake (2002), and early Sheep (2003); their neighboring signs are late Dragon (2001), early Horse (2002), and late Horse (2003). 
Figure 4 Random zodiac signs and parental investment:

In the sample for noncognitive skills
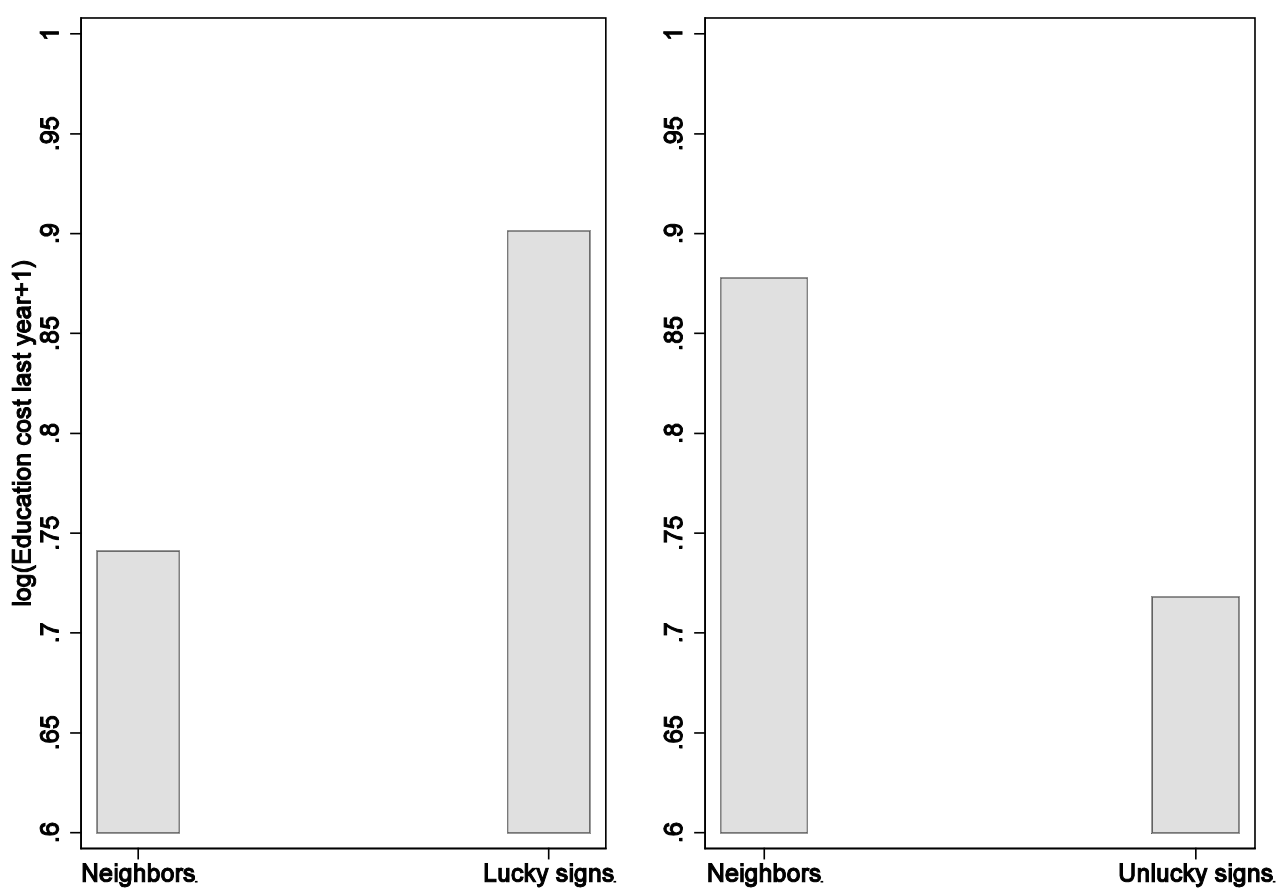

Note: This figure depicts the average parental investments measured as mean log (education cost last year +1 ) between lucky random zodiac signs and their neighboring signs, and between unlucky random zodiac signs and their neighboring signs, in the sample for noncognitive skills. The lucky random zodiac signs include late Tiger (1999), early Dragon (2000), and late Dragon (2001); their neighboring signs include early Rabbit (1999), late Rabbit (2000), and early Snake (2001). The unlucky signs are early Snake (2001), late Snake (2002), early Sheep (2003), and late Sheep (2004); their neighboring signs are late Dragon (2001), early Horse (2002), late Horse (2003), and early Monkey (2004). 
Table 1 The impact of parental investments on children's cognitive skills: Ordinary least squares regressions

\begin{tabular}{|c|c|c|c|c|c|c|c|}
\hline \multirow[b]{2}{*}{ Variable } & \multicolumn{2}{|c|}{ Panel A: Cognitive skills } & \multirow[b]{2}{*}{$\begin{array}{l}\text { Curiosity } \\
\text { (1) }\end{array}$} & \multicolumn{4}{|c|}{ Panel B: Noncognitive skills } \\
\hline & $\begin{array}{l}\text { Word recognition test } \\
\text { (1) }\end{array}$ & $\begin{array}{l}\text { Math test } \\
\text { (2) }\end{array}$ & & $\begin{array}{l}\text { Organization } \\
\text { (2) }\end{array}$ & $\begin{array}{l}\text { Optimism } \\
\text { (3) }\end{array}$ & $\begin{array}{l}\text { Mistake endurance } \\
\text { (4) }\end{array}$ & $\begin{array}{l}\text { Anger control } \\
\text { (5) }\end{array}$ \\
\hline $\begin{array}{l}\text { Log(Education cost } \\
\text { last year+1) }\end{array}$ & $\begin{array}{l}2.072 * * * \\
(0.368)\end{array}$ & $\begin{array}{l}1.167^{* * *} \\
(0.266)\end{array}$ & $\begin{array}{c}0.012 \\
(0.037)\end{array}$ & $\begin{array}{c}0.044 \\
(0.042)\end{array}$ & $\begin{array}{l}0.083^{* * *} \\
(0.025)\end{array}$ & $\begin{array}{l}0.067 * \\
(0.037)\end{array}$ & $\begin{array}{c}0.059 \\
(0.050)\end{array}$ \\
\hline Gender & $\begin{array}{l}-1.791 * * * \\
(0.361)\end{array}$ & $\begin{array}{l}-0.098 \\
(0.232)\end{array}$ & $\begin{array}{c}0.053 \\
(0.054)\end{array}$ & $\begin{array}{l}-0.102 * \\
(0.054)\end{array}$ & $\begin{array}{c}0.039 \\
(0.036)\end{array}$ & $\begin{array}{c}0.014 \\
(0.057)\end{array}$ & $\begin{array}{c}0.040 \\
(0.045)\end{array}$ \\
\hline Urban & $\begin{array}{l}0.960 * * * \\
(0.345)\end{array}$ & $\begin{array}{c}0.284 \\
(0.185)\end{array}$ & $\begin{array}{l}-0.014 \\
(0.054)\end{array}$ & $\begin{array}{l}-0.168 * * * \\
(0.057)\end{array}$ & $\begin{array}{l}-0.047 \\
(0.041)\end{array}$ & $\begin{array}{l}-0.053 \\
(0.061)\end{array}$ & $\begin{array}{l}-0.125^{* *} \\
(0.052)\end{array}$ \\
\hline No. of siblings & $\begin{array}{l}-0.432 \\
(0.287)\end{array}$ & $\begin{array}{l}-0.091 \\
(0.095)\end{array}$ & $\begin{array}{l}-0.020 \\
(0.025)\end{array}$ & $\begin{array}{c}0.035 \\
(0.023)\end{array}$ & $\begin{array}{l}-0.013 \\
(0.021)\end{array}$ & $\begin{array}{l}-0.003 \\
(0.025)\end{array}$ & $\begin{array}{c}0.031 \\
(0.028)\end{array}$ \\
\hline Father's age & $\begin{array}{l}-0.017 \\
(0.062)\end{array}$ & $\begin{array}{l}-0.046 \\
(0.034)\end{array}$ & $\begin{array}{l}-0.014 * \\
(0.008)\end{array}$ & $\begin{array}{c}0.006 \\
(0.009)\end{array}$ & $\begin{array}{c}0.001 \\
(0.005)\end{array}$ & $\begin{array}{l}-0.001 \\
(0.009)\end{array}$ & $\begin{array}{l}-0.012 \\
(0.010)\end{array}$ \\
\hline $\begin{array}{l}\text { Father's } \\
\text { education }\end{array}$ & $\begin{array}{l}0.206^{* * *} \\
(0.057)\end{array}$ & $\begin{array}{l}0.110^{* * *} \\
(0.031)\end{array}$ & $\begin{array}{l}0.017^{* *} \\
(0.009)\end{array}$ & $\begin{array}{c}0.005 \\
(0.009)\end{array}$ & $\begin{array}{l}-0.004 \\
(0.006)\end{array}$ & $\begin{array}{l}-0.001 \\
(0.010)\end{array}$ & $\begin{array}{l}-0.009 \\
(0.008)\end{array}$ \\
\hline Mother's age & $\begin{array}{c}0.059 \\
(0.054)\end{array}$ & $\begin{array}{l}0.087^{* *} \\
(0.038)\end{array}$ & $\begin{array}{c}0.010 \\
(0.007)\end{array}$ & $\begin{array}{c}0.007 \\
(0.010)\end{array}$ & $\begin{array}{c}0.009 * \\
(0.005)\end{array}$ & $\begin{array}{c}0.006 \\
(0.008)\end{array}$ & $\begin{array}{l}0.023^{* *} \\
(0.010)\end{array}$ \\
\hline $\begin{array}{l}\text { Mother's } \\
\text { education }\end{array}$ & $\begin{array}{c}0.113^{*} \\
(0.064)\end{array}$ & $\begin{array}{l}0.099 * * * \\
(0.036)\end{array}$ & $\begin{array}{c}0.003 \\
(0.007)\end{array}$ & $\begin{array}{l}-0.009 \\
(0.009)\end{array}$ & $\begin{array}{c}0.010 \\
(0.007)\end{array}$ & $\begin{array}{l}-0.001 \\
(0.007)\end{array}$ & $\begin{array}{c}0.001 \\
(0.009)\end{array}$ \\
\hline $\begin{array}{l}\text { Log(Family } \\
\text { Income+1) }\end{array}$ & $\begin{array}{l}0.728^{* * *} \\
(0.200)\end{array}$ & $\begin{array}{l}0.354^{* * *} \\
(0.118)\end{array}$ & $\begin{array}{c}0.022 \\
(0.018)\end{array}$ & $\begin{array}{l}-0.020 \\
(0.020)\end{array}$ & $\begin{array}{l}-0.003 \\
(0.011)\end{array}$ & $\begin{array}{c}0.012 \\
(0.020)\end{array}$ & $\begin{array}{c}0.011 \\
(0.031)\end{array}$ \\
\hline $\begin{array}{l}R^{2} \\
\text { Observations }\end{array}$ & $\begin{array}{l}0.249 \\
1,098\end{array}$ & $\begin{array}{l}0.275 \\
1,098\end{array}$ & $\begin{array}{l}0.089 \\
1,257\end{array}$ & $\begin{array}{l}0.024 \\
1,257\end{array}$ & $\begin{array}{l}0.067 \\
1,257\end{array}$ & $\begin{array}{c}0.072 \\
1,257\end{array}$ & $\begin{array}{l}0.083 \\
1,257\end{array}$ \\
\hline
\end{tabular}

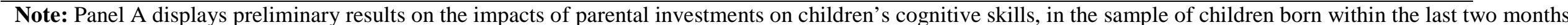
or the first two months of a lunar year. Panel B displays preliminary results for the impacts of parental investment on children's noncognitive skills, in the sample of children born in the last two months or first two months of a lunar year. Appendix Table A.2 provides detailed explanations for all variables. All regressions are

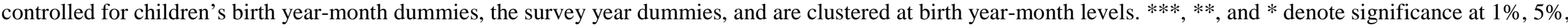
and $10 \%$, respectively. 
Table 2 The impact of parental investments on children's cognitive skills: First-stage regression

\begin{tabular}{|c|c|c|}
\hline Variable & Log(Education cost last year+1) & Zodiac sign category \\
\hline Late Rat & $\begin{array}{l}0.500^{* * *} \\
(0.118)\end{array}$ & Neutral (1997) \\
\hline Early Ox & $\begin{array}{l}0.390^{* * *} \\
(0.114)\end{array}$ & Neutral (1997) \\
\hline Late Ox & $\begin{array}{l}0.255^{* *} \\
(0.113)\end{array}$ & Neutral (1998) \\
\hline Early Tiger & $\begin{array}{l}0.251^{* *} \\
(0.110)\end{array}$ & Lucky (1998) \\
\hline Late Tiger & $\begin{array}{l}0.650^{* * *} \\
(0.097)\end{array}$ & Lucky (1999) \\
\hline Early Rabbit & $\begin{array}{l}0.496^{* * *} \\
(0.092)\end{array}$ & Neutral (1999) \\
\hline Late Rabbit & $\begin{array}{l}0.216^{* *} \\
(0.092)\end{array}$ & Neutral (2000) \\
\hline Early Dragon & $\begin{array}{l}0.294^{* * *} \\
(0.092)\end{array}$ & Lucky (2000) \\
\hline Late Dragon & $\begin{array}{l}0.241 * * * \\
(0.091)\end{array}$ & Lucky (2001) \\
\hline Early Snake & $\begin{array}{l}-0.089 \\
(0.105)\end{array}$ & Unlucky (2001) \\
\hline Late Snake & $\begin{array}{l}-0.253^{* *} \\
(0.120)\end{array}$ & Unlucky (2002) \\
\hline Early Horse & $\begin{array}{c}0.088 \\
(0.111)\end{array}$ & Neutral (2002) \\
\hline Late Horse & $\begin{array}{c}0.126 \\
(0.116)\end{array}$ & Neutral (2003) \\
\hline Early Sheep & $\begin{array}{c}0.050 \\
(0.115)\end{array}$ & Unlucky (2003) \\
\hline $\begin{array}{l}\text { Other controls } \\
R^{2}\end{array}$ & Yes & \\
\hline $\begin{array}{l}R^{2} \\
F \text {-test for lucky coef. }=\text { other coef. } \\
\text { (Prob. }>F \text { ) }\end{array}$ & $\begin{array}{l}0.284 \\
3.28^{* * *} \\
(0.01)\end{array}$ & \\
\hline $\begin{array}{l}\text { F-test for unlucky coef. }=\text { other coef. } \\
\text { (Prob. }>\text { F) }\end{array}$ & $\begin{array}{l}5.46^{* * *} \\
(0.01)\end{array}$ & \\
\hline $\begin{array}{l}\text { F-test for neutral coef.=neutral coef. } \\
\text { (Prob. }>\text { F) }\end{array}$ & $\begin{array}{c}0.94 \\
(0.33)\end{array}$ & \\
\hline $\begin{array}{l}\text { Kleibergen-Paap Wald } F \\
\text { Hansen's } J \text { statistic } \\
(p \text { for Hansen's } J) \\
\text { Observations }\end{array}$ & $\begin{array}{c}22.583^{*} \\
23.103^{*} \\
(0.059) \\
1,098 \\
\end{array}$ & \\
\hline
\end{tabular}

Note: The sample includes all children that were born within the last two months or first two months of a lunar year and have cognitive skill test results available. Appendix Table A.2 provides detailed explanations for all variables. Children born in 2004 are used as the reference. Other control variables include gender, urban dummy, number of siblings, father's age and education, mother's age and education, logged family income, and the survey year dummies. All regressions are clustered at children's birth year-month levels. The F-test between lucky and other zodiac coefficients is a joint test of (late Ox = early Tiger), (late Tiger = early Rabbit), (late Rabbit=early Dragon), and (late Dragon = early Snake). The F-test between unlucky and other zodiac coefficients is a joint test of (late Dragon = early Snake), (late Snake = early Horse), and (late Horse=early Sheep). The F-test between neutral zodiac coefficients is a test of (late Rat $=$ early Ox). The significance for the Kleibergen-Paap Wald $F$ is from the Stock-Yogo weak instrument test. ***, ${ }^{* *}$, and $*$ denote significance at $1 \%, 5 \%$, and $10 \%$, respectively. 
Table 3 The impact of parental investments on children's cognitive skills: Second-stage regression

\begin{tabular}{lcc}
\hline Variable & $\begin{array}{c}\text { Word recognition test } \\
(1)\end{array}$ & $\begin{array}{c}\text { Math test } \\
(2)\end{array}$ \\
\cline { 2 - 3 } Log(Education cost & $7.176^{* * *}$ & $3.742^{* * *}$ \\
last year+1) & $(1.705)$ & $(1.029)$ \\
Gender & $-1.608^{* * *}$ & 0.010 \\
& $(0.405)$ & $(0.212)$ \\
Urban & 0.448 & 0.121 \\
& $(0.420)$ & $(0.315)$ \\
No. of siblings & -0.448 & -0.163 \\
& $(0.420)$ & $(0.173)$ \\
Father's age & -0.034 & $-0.069^{*}$ \\
Father's & $(0.066)$ & $(0.041)$ \\
education & $0.199^{* * *}$ & $0.103^{* * *}$ \\
Mother's age & $(0.060)$ & $(0.032)$ \\
& 0.044 & $0.102^{* * *}$ \\
Mother's & $(0.057)$ & $(0.039)$ \\
education & -0.071 & -0.004 \\
Log(Family income+1) & $(0.099)$ & $(0.053)$ \\
& -0.303 & -0.244 \\
$R^{2}$ & $(0.283)$ & $0.163)$ \\
Observations & 0.043 & 0.052 \\
\hline Note: This & 1,098 & 1,098 \\
\hline
\end{tabular}

Note: This table displays the second-stage regression results for the impacts of parental investment on children's cognitive skills. The sample includes all children for whom cognitive skill test results are available (birth years 1997 through 2004) and who were born within the last two months or the first two months of a lunar year. Appendix Table A.2 provides detailed explanations for all variables. Children born in 2004 are used as the reference. All regressions are clustered at children's birth year-month levels. ${ }^{* *},{ }^{* *}$, and $*$ denote significance at $1 \%, 5 \%$, and $10 \%$, respectively. 
Table 4 The impact of parental investments on children's noncognitive skills

\begin{tabular}{|c|c|c|c|c|c|}
\hline Variable & $\frac{\text { Curiosity }}{(1)}$ & $\frac{\text { Organization }}{(2)}$ & $\frac{\text { Optimism }}{(3)}$ & $\frac{\text { Mistake tolerance }}{(4)}$ & $\frac{\text { Anger control }}{(5)}$ \\
\hline $\begin{array}{l}\text { Log(Education } \\
\text { Cost last year }+1)\end{array}$ & $\begin{array}{l}0.149 * \\
(0.088)\end{array}$ & $\begin{array}{l}0.295^{* * *} \\
(0.071)\end{array}$ & $\begin{array}{l}-0.012 \\
(0.060)\end{array}$ & $\begin{array}{l}0.327 * * * \\
(0.087)\end{array}$ & $\begin{array}{l}0.544 * * * \\
(0.094)\end{array}$ \\
\hline Gender & $\begin{array}{c}0.076 \\
(0.052)\end{array}$ & $\begin{array}{l}-0.079 \\
(0.053)\end{array}$ & $\begin{array}{c}0.044 \\
(0.035)\end{array}$ & $\begin{array}{c}0.027 \\
(0.054)\end{array}$ & $\begin{array}{c}0.063 \\
(0.049)\end{array}$ \\
\hline Urban & $\begin{array}{l}-0.076 \\
(0.050)\end{array}$ & $\begin{array}{l}-0.229^{* * *} \\
(0.060)\end{array}$ & $\begin{array}{l}-0.045 \\
(0.033)\end{array}$ & $\begin{array}{l}-0.103^{* *} \\
(0.052)\end{array}$ & $\begin{array}{l}-0.229^{* * *} \\
(0.052)\end{array}$ \\
\hline No. of siblings & $\begin{array}{c}0.002 \\
(0.023)\end{array}$ & $\begin{array}{l}0.062^{* *} \\
(0.024)\end{array}$ & $\begin{array}{l}-0.013 \\
(0.019)\end{array}$ & $\begin{array}{c}0.015 \\
(0.026)\end{array}$ & $\begin{array}{l}0.075^{* *} \\
(0.031)\end{array}$ \\
\hline Father's age & $\begin{array}{l}-0.019 * * * \\
(0.007)\end{array}$ & $\begin{array}{c}0.001 \\
(0.008)\end{array}$ & $\begin{array}{l}-0.002 \\
(0.005)\end{array}$ & $\begin{array}{l}-0.001 \\
(0.008)\end{array}$ & $\begin{array}{l}-0.015^{*} \\
(0.009)\end{array}$ \\
\hline $\begin{array}{l}\text { Father's } \\
\text { education }\end{array}$ & $\begin{array}{l}0.016^{* *} \\
(0.008)\end{array}$ & $\begin{array}{c}0.002 \\
(0.009)\end{array}$ & $\begin{array}{l}-0.003 \\
(0.006)\end{array}$ & $\begin{array}{l}-0.006 \\
(0.009)\end{array}$ & $\begin{array}{l}-0.017^{* *} \\
(0.008)\end{array}$ \\
\hline Mother's age & $\begin{array}{c}0.009 \\
(0.007)\end{array}$ & $\begin{array}{l}-0.001 \\
(0.008)\end{array}$ & $\begin{array}{c}0.005 \\
(0.005)\end{array}$ & $\begin{array}{c}0.008 \\
(0.008)\end{array}$ & $\begin{array}{l}0.020^{* * *} \\
(0.009)\end{array}$ \\
\hline $\begin{array}{l}\text { Mother's } \\
\text { education }\end{array}$ & $\begin{array}{c}0.002 \\
(0.007)\end{array}$ & $\begin{array}{l}-0.015 \\
(0.009)\end{array}$ & $\begin{array}{l}0.015^{* *} \\
(0.007)\end{array}$ & $\begin{array}{l}-0.008 \\
(0.007)\end{array}$ & $\begin{array}{l}-0.012 \\
(0.008)\end{array}$ \\
\hline Family income & $\begin{array}{c}0.021 \\
(0.020)\end{array}$ & $\begin{array}{l}-0.043^{* *} \\
(0.022)\end{array}$ & $\begin{array}{c}0.013 \\
(0.013)\end{array}$ & $\begin{array}{l}-0.003 \\
(0.021)\end{array}$ & $\begin{array}{l}-0.012 \\
(0.031)\end{array}$ \\
\hline $\begin{array}{l}R^{2} \\
\text { Observations }\end{array}$ & $\begin{array}{l}0.020 \\
1,257\end{array}$ & $\begin{array}{c}0.019 \\
1,257\end{array}$ & $\begin{array}{l}0.011 \\
1,257\end{array}$ & $\begin{array}{c}0.013 \\
1,257\end{array}$ & $\begin{array}{l}0.064 \\
1,257\end{array}$ \\
\hline
\end{tabular}

Note: This table displays the second-stage regression results for the impacts of parental investment on children's noncognitive skills. The sample includes all children for whom noncognitive skill test results are available and whose birth dates fall in the last or first two months of a lunar year. Appendix Table A.2 provides detailed explanations for all variables. All regressions are clustered at children's birth year-month levels. ***, **, and * denote significance at $1 \%, 5 \%$, and $10 \%$, respectively. 


\section{Table 5 Falsification tests: Children born in the same lunar year}

\begin{tabular}{|c|c|c|}
\hline $\begin{array}{l}F \text {-test for group } 1 \text { coef.=group } 2 \text { coef. in a } \\
\text { lucky year } \\
\text { (Prob. }>F \text { ) }\end{array}$ & $\begin{array}{l}\text { (1) Sample for cognitive skills } \\
\text { Log(Education cost last year) } \\
0.07\end{array}$ & $\begin{array}{l}\text { (2) Sample for noncognitive skills } \\
\text { Log(Education cost last year } \\
0.04\end{array}$ \\
\hline $\begin{array}{l}\text { F-test for unlucky group } 1 \text { coef.=gro } \\
\text { coef. in an unlucky year } \\
\text { (Prob. }>F \text { ) }\end{array}$ & $(0.93)$ & $(0.76)$ \\
\hline $\begin{array}{l}F \text {-test for group l coef.=group } 2 \text { coef. In a } \\
\text { neutral year } \\
\text { (Prob. }>F \text { ) }\end{array}$ & $(0.38)$ & $(0.12)$ \\
\hline $\begin{array}{l}\text { Kleibergen-Paap Wald F } \\
\text { Observations }\end{array}$ & $\begin{array}{c}39.062 \\
912\end{array}$ & $\begin{array}{l}40.803^{* *} \\
1,139\end{array}$ \\
\hline \multicolumn{3}{|c|}{$\begin{array}{l}\text { Note: This table displays the results of falsification tests. The sample for cognitive skills includes all children that were born in } \\
\text { the third to sixth month of a lunar year and have taken cognitive skill tests; the sample for noncognitive skills includes all } \\
\text { children that were born in the third to sixth month of a lunar year and have taken noncognitive skill tests. The two groups in } \\
\text { each lunar year are children who were born in the third and fourth months (group 1) and in the fifth and sixth months (group } 2 \text { ) } \\
\text { in that lunar year. All regressions are controlled for children's gender, region, number of siblings, parents' age and education, } \\
\text { family income, and the survey year dummies, and are clustered at children's birth year-month levels. In column (1), the first } \\
\text { stage regression shows the logged education cost can be explained by children's group } 1 \text { and } 2 \text { zodiac signs. Children that } \\
\text { were born in } 2004 \text { are used as the reference. The F-test is a joint test for whether coefficients of the first and second groups in } \\
\text { the lucky/unlucky/neutral lunar year are equal. The lucky years include Tiger (1998) and Dragon (2000); the unlucky years } \\
\text { include Snake (2001) and Sheep (2003); the neutral years include Ox (1997), Rabbit (1999), and Horse (2002). In column (2), } \\
\text { children that were born in } 2010 \text { are used as the reference for the first stage regression. The F-test is a joint test for whether } \\
\text { coefficients of the first and second groups in the lunar year are equal. The lucky year includes Dragon (2000); the unlucky } \\
\text { years include Snake (2001) and Sheep (2003); the neutral years include Ox (1997), Rabbit (1999), Horse (2002), Monkey } \\
\text { (2004), Rooster (2005), Dog } 2 \text { (2006), Pig } 2 \text { (2007), Ox 2(2009). ***, **, and * denote significance at 1\%, 5\%, and 10\%, } \\
\text { respectively. }\end{array}$} \\
\hline
\end{tabular}


Table 6 The impact of parental investments on children's skills: An alternative window

\begin{tabular}{|c|c|c|c|c|c|c|c|}
\hline \multirow[t]{3}{*}{ Variable } & \multicolumn{2}{|c|}{ Panel A: Cognitive skills } & \multicolumn{5}{|c|}{ Panel B: Noncognitive skills } \\
\hline & $\underline{\text { Word recognition test }}$ & $\underline{\text { Math test }}$ & Curiosity & $\underline{\text { Organization }}$ & $\underline{\text { Optimism }}$ & $\underline{\text { Mistake tolerance }}$ & Anger control \\
\hline & (1) & (2) & (1) & (2) & (3) & (4) & (5) \\
\hline Log(Education & $7.757 * * *$ & $4.527 * * *$ & 0.098 & $0.215^{* * *}$ & -0.045 & $0.313^{* * *}$ & $0.483^{* * *}$ \\
\hline cost last year+1) & $(1.770)$ & $(1.038)$ & $(0.108)$ & $(0.083)$ & $(0.067)$ & $(0.098)$ & $(0.098)$ \\
\hline$R^{2}$ & 0.131 & 0.163 & 0.033 & 0.010 & 0.016 & 0.014 & 0.050 \\
\hline Observations & 1,105 & 1,105 & 1,190 & 1,190 & 1,190 & 1,190 & 1,190 \\
\hline
\end{tabular}

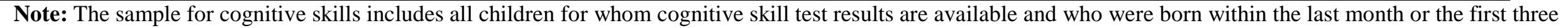
months of a lunar year; the sample for noncognitive skills includes all children for whom noncognitive skill test results are available and who were born within the last month or the first three months of a lunar year. All regressions are controlled for children's gender, region, number of siblings, parents' age and education, family income, and the survey year dummies, and are clustered at children's birth year-month levels. Children born in 2004 and in 2010 are used as the reference in regressions for cognitive skills and noncognitive skills respectively. Appendix Table A.2 provides detailed explanations for all variables. ***, **, and * denote significance at $1 \%$, $5 \%$, and $10 \%$, respectively. 
Table 7 The impact of parental investments on children's skills: Children's self-consciousness

\begin{tabular}{|c|c|c|c|c|c|c|c|}
\hline \multirow[t]{3}{*}{ Variable } & \multicolumn{2}{|c|}{ Panel A: Cognitive skills } & \multicolumn{5}{|c|}{ Panel B: Noncognitive skills } \\
\hline & Word recognition test & Math test & Curiosity & Organization & Optimism & Mistake tolerance & Anger control \\
\hline & (1) & (2) & (1) & (2) & (3) & (4) & (5) \\
\hline Log(Education & $2.856 * *$ & -0.255 & $0.260 * * *$ & $0.304 * * *$ & 0.001 & $0.467 * * *$ & $0.592 * * *$ \\
\hline cost last year+1) & $(1.360)$ & $(0.684)$ & $(0.096)$ & $(0.930)$ & $(0.109)$ & $(0.110)$ & $(0.102)$ \\
\hline$R^{2}$ & 0.147 & 0.120 & 0.008 & 0.032 & 0.015 & 0.047 & 0.100 \\
\hline Observations & 653 & 653 & 1,090 & 1,090 & 1,090 & 1,090 & 1,090 \\
\hline
\end{tabular}

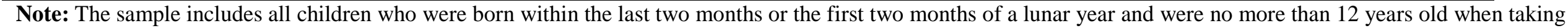
the survey. Children born in 2004 and in 2010 are used as the reference in regressions for cognitive skills and noncognitive skills respectively. All regressions are controlled for children's gender, region, number of siblings, parents' age and education, family income, and the survey year dummies, and are clustered at children's birth year-month levels. Appendix Table A.2 provides detailed explanations for all variables. ***, **, and * denote significance at $1 \%$, $5 \%$, and $10 \%$, respectively. 
Table 8 The impact of parental investments on children's skills: Children's self-confidence

\begin{tabular}{lcc}
\hline Variable & Word recognition test & Math test \\
& $(1)$ & $(2)$ \\
\cline { 2 - 3 } Log(Education cost & $8.777 * * *$ & $5.892^{* * *}$ \\
last year+1) & $(1.689)$ & $(0.998)$ \\
Equal & -0.426 & -0.047 \\
& $(0.564)$ & $(0.277)$ \\
Quality & 0.216 & -0.351 \\
& $(0.523)$ & $(0.259)$ \\
Do well & 0.658 & 0.342 \\
& $(0.860)$ & $(0.459)$ \\
Positive & 0.014 & 0.200 \\
& $(0.299)$ & $(0.225)$ \\
Satisfy & -0.462 & -0.158 \\
& $(0.651)$ & $(0.303)$ \\
Respect & $1.095 *$ & 0.360 \\
& $(0.655)$ & $(0.349)$ \\
Control & 0.370 & 0.038 \\
& $(0.456)$ & $(0.186)$ \\
$R^{2}$ & 0.049 & 0.025 \\
Observations & 430 & 430 \\
\hline Note: The sample includes all children who were born within the last two months or the first two months of a \\
lunar year. Children born in 2004 are used as the reference in regressions. All regressions are controlled for \\
children's gender, region, number of siblings, parents’ age and education, family income, and the survey \\
year dummies, and are clustered at children’s birth year-month levels. Appendix Table A.2 provides detailed \\
explanations for all variables. ***, **, and * denote significance at 1\%, 5\%, and 10\%, respectively.
\end{tabular}


Table 9 The impact of parental investments on children's skills: One Child Only

\begin{tabular}{|c|c|c|c|c|c|c|c|}
\hline \multirow[t]{3}{*}{ Variable } & \multicolumn{2}{|c|}{ Panel A: Cognitive skills } & \multicolumn{5}{|c|}{ Panel B: Noncognitive skills } \\
\hline & Word recognition test & Math test & Curiosity & Organization & Optimism & Mistake tolerance & Anger control \\
\hline & (1) & (2) & (1) & $(2)$ & (3) & (4) & (5) \\
\hline Log(Education & $5.957 * * *$ & $3.162 * * *$ & 0.122 & $0.314 * * *$ & 0.013 & $0.250 * *$ & $0.385 * * *$ \\
\hline cost last year+1) & $(2.254)$ & $(0.762)$ & $(0.102)$ & $(0.119)$ & $(0.101)$ & $(0.115)$ & $(0.119)$ \\
\hline$R^{2}$ & 0.049 & 0.051 & 0.018 & 0.042 & 0.040 & 0.001 & 0.017 \\
\hline Observations & 429 & 429 & 519 & 519 & 519 & 519 & 519 \\
\hline
\end{tabular}

Note: The sample includes all children who were born within the last two months or the first two months of a lunar year and were the only child in the household. Children born in 2004 and in 2010 are used as the reference in regressions for cognitive skills and noncognitive skills respectively. All regressions are controlled for children's gender, region, number of siblings, parents' age and education, family income, and the survey year dummies, and are clustered at children's birth year-month levels. Appendix Table A.2 provides detailed explanations for all variables. ${ }^{* * *}$, **, and * denote significance at $1 \%$, $5 \%$, and $10 \%$, respectively. 


\section{References}

Adhvaryu, A., and A. Nyshadham. 2016. “Endowments at Birth and Parents' Investments in Children.” Economic Journal 126:781-820.

Anger, S., and D. D. Schnitzlein, 2017. “Cognitive Skills, Non-cognitive Skills, and Family Background: Evidence from Sibling Correlations.” Journal of Population Economics 30 (2): 591-620.

Beaman, E. E Duflo, R Pande, and P. Topolova. 2012. "Female Leadership Raises Aspirations and Educational Attainment for Girls: A Policy Experiment in India.” Science 335 (6068): 582-586.

Blume, L., W. Brock, S. N. Durlauf, and Y. Ioannides. 2011. "Identification of Social Interactions.” In Handbook of Social Economics, edited by J. Benhabib, A. Bisin, and M. Jackson, 853-964. Amsterdam: North Holland.

Boneva, T., and C. Rauh. 2018. "Parental Beliefs about Returns to Educational Investment-The Later the Better?” Journal of European Economic Association 16 (6), 1669-1711.

Borghans, L., A. L. Duckworth, J. Heckman, and B. ter Weel. 2008. "The Economics and Psychology of Personality Traits.” Journal of Human Resources 43 (4): 972-1059.

Cadena, B. C., and B. J. Keys. 2015. "Human Capital and the Lifetime Costs of Impatience.” American Economic Journal: Economic Policy 7 (3): 126-153.

Carneiro, P., and J. Heckman. 2005. "Human Capital Policy.” In Inequality in America: What Role for Human Capital Policies? edited by B. M. Friedman, 77-208. Cambridge, MA, US: MIT Press.

Chetty, R., J. N. Friedman, N. Hilger, E. Saez, D. W. Schanzenbach, and D. Yagan. 2011. “How Does Your Kindergarten Classroom Affect Your Earnings? Evidence from Project Star.” The Quarterly Journal of Economics 126 (4): 1593-1660.

Cima, R. 2015. “How The Chinese Zodiac Affects National Birth Rates.” Priceonomics, Feb 24. https://priceonomics.com/how-the-chinese-zodiac-affects-national-birth/ 
Cunha, F., and J. Heckman. 2008. "Formulating, Identifying and Estimating the Technology of Cognitive and Noncognitive Skill Formation.” The Journal of Human Resources 43 (4): 738-782.

Cunha, F., J. Heckman, and S. M. Schennach. 2010. "Estimating the Technology of Cognitive and Noncognitive Skill Formation.” Econometrica 78 (3): 883-931.

Do, Q., and T. D. Phung. 2010. “The Importance of Being Wanted.” American Economic Journal: Applied Economics 2 (4): 236-253.

Durlauf, S. N., and Y. Ioannides. 2010. “Social Interactions.” Annual Review of Economics 2:451-478.

Hanushek, E. A., and D. K. Dennis. 2000. “Schooling, Labor-Force Quality, and the Growth of Nations.” American Economic Review 90 (5): 1184-1208.

Hanushek, E. A., and L. Woessmann. 2008. "The Role of Cognitive Skills in Economic Development.” Journal of Economic Literature 46 (3): 607-668.

Heckman, J., and S. Mosso. 2014. “The Economics of Human Development and Social Mobility.” Annual Review of Economics 6:689-733.

Heckman, J., R. Pinto, and P. Savelyev. 2013. “Understanding the Mechanisms through Which an Influential Early Childhood Program Boosted Adult Outcomes.” American Economic Review 103 (6): 2052-2086.

Heckman, J., and Y. Rubinstein. 2001. “The Importance of Noncognitive Skills: Lessons from the GED Testing Program.” American Economic Review 91 (2): 145-149.

Heckman, J., J. Stixrud, and S. Urzua. 2006. “The Effects of Cognitive and Noncognitive Abilities on Labor Market Outcomes and Social Behavior.” Journal of Labor Economics 24 (3): 411-482.

Huang, W., X. Lei, and Y. Zhao. 2016. “One-Child Policy and the Rise of Man-Made Twins.” Review of Economics and Statistics 98 (3): 467-476.

Johnson, N. D., and J. V. C. Nye. 2011. “Does Fortune Favor Dragons? Journal of Economic Behavior \& Organization 78 (1): 85-97.

Kirchsteiger, G., and A. Sebald, 2010. “Investments into Education-Doing as the Parents Did.” European Economic Review 54 (4): 501-516. 
Leight, J., P. Glewwe, and A. Park. 2015. The Impact of Early Childhood Rainfall Shocks on the Evolution of Cognitive and Non-cognitive Skills. Gansu Survey of Children and Families Paper 51. Philadelphia: University of Pennsylvania.

Lim, R. 2012. "Enter the Dragons: A Baby Boom for Chinese across Asia.” BBC News, January 20. www.bbc.com/news/world-asia-16589052.

Lu, S., and K. Hunt, 2015. "Chinese Couples Shun Year of the Sheep babies,” CNN News, February 15. https://www.cnn.com/2015/02/08/asia/china-sheep-babies/index.html.

Ludwig, J., and D. L. Miller. 2007. “Does Head Start Improve Children’s Life Chances?

Evidence from a Regression Discontinuity Design.” The Quarterly Journal of Economics 122 (1): 159-208.

Mocan, N. H., and H. Yu. 2017. "Can Superstition Create a Self-fulfilling Prophecy? School Outcomes of Dragon Children of China.” National Bureau of Economic Research Working Paper 23709.

Sen, A., 1999. Development as Freedom. Oxford University Press.

Shonkoff, J. P., and D. A. Phillips. 2000. From Neurons to Neighborhoods: The Science of Early Childhood Development. Washington, DC: National Academies Press.

Tan, C. M., Z. Tan, and X. Zhang. 2015. Sins of the Fathers: The Intergenerational Legacy of the 1959-61 Great Chinese Famine on Children's Cognitive Development. Discussion Paper 1351. Washington, DC: International Food Policy Research Institute.

Vere, J. P. 2008. "Dragon Children: Identifying the Causal Effect of the First Child on Female Labour Supply with the Chinese Lunar Calendar." Oxford Bulletin of Economics and Statistics 70:303-325.

Wan, W., 2014. "Chinese Couples Rush to Get Pregnant Before Dreaded Year of the Sheep," Washington Post, May 9. http://wapo.st/1st8MnB?tid=ss_mail\&utm_term=.519213c0558c

Wang, Q., 2014. "Babies Bloom in Propitious Years of the Chinese Zodiac,” China Daily, May 14. http://www.chinadaily.com.cn/china/2014-05/14/content_17505363.htm

Wong, K. F., and L. Yung. 2005. “Do Dragons Have Better Fate?” Economic Inquiry 43 (3): 689-697. 
Zhang, H., J. Behrman, S. Fan, X. Wei and J. Zhang, 2014. “Does Parental Absence Reduce Cognitive Achievements? Evidence from Rural China.” Journal of Development Economics 111: 181-195. 


\section{Appendix A}

\section{Table A.1 Birth rates in the middle months of lunar years}

Panel A Lucky zodiac signs

\begin{tabular}{|c|c|c|c|c|c|c|c|c|c|c|c|c|}
\hline & \multicolumn{6}{|c|}{ Tiger } & \multicolumn{6}{|c|}{ Dragon } \\
\hline & \multicolumn{3}{|c|}{ Born in the middle 8 months } & \multicolumn{3}{|c|}{ Born in the middle 10 months } & \multicolumn{3}{|c|}{ Born in the middle 8 months } & \multicolumn{3}{|c|}{ Born in the middle 10 months } \\
\hline $\begin{array}{l}\text { Recent } 3 \text { zodiac } \\
\text { cycles }\end{array}$ & 0.681 & 0.676 & $3.550^{* * *}$ & 0.841 & 0.838 & $2.326^{* *}$ & 0.697 & 0.675 & $15.170^{* * *}$ & 0.868 & 0.836 & $28.895^{* * *}$ \\
\hline No. of obs. & 114,552 & $1,153,596$ & & 114,552 & $1,153,596$ & & 108,965 & $1,159,183$ & & 108,965 & $1,159,183$ & \\
\hline $\begin{array}{c}\text { Recent } 5 \text { zodiac } \\
\text { cycles }\end{array}$ & 0.682 & 0.676 & $5.534 * * *$ & 0.843 & 0.841 & $2.398^{* *}$ & 0.687 & 0.675 & $10.975 * * *$ & 0.856 & 0.840 & $19.257 * * *$ \\
\hline No. of obs. & 192,075 & $2,030,242$ & & 192,075 & $2,030,242$ & & 192,226 & $2,030,091$ & & 192,226 & $2,030,091$ & \\
\hline
\end{tabular}

Panel B Unlucky zodiac signs

\begin{tabular}{|c|c|c|c|c|c|c|c|c|c|c|c|c|}
\hline & \multicolumn{6}{|c|}{ Snake } & \multicolumn{6}{|c|}{ Sheep } \\
\hline & \multicolumn{3}{|c|}{ Born in the middle 8 months } & \multicolumn{3}{|c|}{ Born in the middle 10 months } & \multicolumn{3}{|c|}{ Born in the middle 8 months } & \multicolumn{3}{|c|}{ Born in the middle 10 months } \\
\hline & Snake & Others & $t$ & Snake & Others & $t$ & Sheep & Others & $t$ & Sheep & Others & $t$ \\
\hline $\begin{array}{l}\text { Recent } 3 \text { zodiac } \\
\text { cycles }\end{array}$ & 0.673 & 0.677 & $-2.350^{* *}$ & 0.840 & 0.839 & 1.124 & 0.674 & 0.676 & $-1.718^{*}$ & 0.836 & 0.839 & $-2.452^{* *}$ \\
\hline No. of obs. & 112,872 & $1,155,276$ & & 112,872 & $1,155,276$ & & 107,198 & $1,160,950$ & & 107,198 & $1,160,950$ & \\
\hline $\begin{array}{l}\text { Recent } 5 \text { zodiac } \\
\text { cycles }\end{array}$ & 0.673 & 0.676 & $-3.214 * * *$ & 0.841 & 0.841 & 0.144 & 0.670 & 0.677 & $-5.534 * * *$ & 0.838 & 0.841 & $-3.776^{* * *}$ \\
\hline No. of obs. & 198,219 & $2,024,098$ & & 198,219 & $2,024,098$ & & 189,935 & $2,030,382$ & & 189,935 & $2,030,382$ & \\
\hline
\end{tabular}

Note: A zodiac cycle refers to a set of twelve years from the year of Rat to the year of Pig.

Data resource: 2005 mini-census by National Bureau of Statistics of China. 


\section{Table A.2 Summary Statistics}

Panel A. Definitions of variables

\begin{tabular}{|c|c|}
\hline Variable & Definition \\
\hline Word test & $\begin{array}{l}\text { The child's word recognition test score based on the number of questions answered correctly. Minimum: } \\
0 \text {, maximum: } 34 \text {. }\end{array}$ \\
\hline Math test & $\begin{array}{l}\text { The child's math test score based on the number of questions answered correctly. Minimum: 0, maximum: } \\
24 \text {. }\end{array}$ \\
\hline Curiosity & $\begin{array}{l}\text { The parent's answer on whether the child is curious. 1: strongly disagree, 2: disagree, 3: neutral, 4: agree, } \\
\text { 5: strongly agree. }\end{array}$ \\
\hline Organization & $\begin{array}{l}\text { The parent's answer on whether the child is organized. 1: strongly disagree, 2: disagree, 3: neutral, 4: } \\
\text { agree, 5: strongly agree. }\end{array}$ \\
\hline Optimism & $\begin{array}{l}\text { The parent's answer on whether the child is optimistic. 1: strongly disagree, 2: disagree, 3: neutral, 4: } \\
\text { agree, 5: strongly agree. }\end{array}$ \\
\hline $\begin{array}{l}\text { Mistake } \\
\text { tolerance }\end{array}$ & $\begin{array}{l}\text { The parent's answer on whether the child can tolerate others' mistakes. 1: strongly disagree, 2: disagree, 3: } \\
\text { neutral, 4: agree, 5: strongly agree. }\end{array}$ \\
\hline Anger control & $\begin{array}{l}\text { The parent's answer on whether the child can control his or her anxiety/anger. 1: strongly disagree, 2: } \\
\text { disagree, 3: neutral, 4: agree, 5: strongly agree. }\end{array}$ \\
\hline $\begin{array}{r}\text { Total education } \\
\text { cost last year }\end{array}$ & $\begin{array}{l}\text { The total real expenditure by parents on the child's education last year (thousand RMB, } 2010 \text { as the base } \\
\text { year). }\end{array}$ \\
\hline Gender & The child's gender: 1 male, 0 female. \\
\hline Urban & If the child lives in the urban area: 1 yes, 0 no. \\
\hline No. of siblings & Number of siblings. \\
\hline Family income & The total real income of the family last year (thousand RMB, 2010 as the base year). \\
\hline Father's age & The father's age. \\
\hline $\begin{array}{l}\text { Father’s } \\
\text { education }\end{array}$ & $\begin{array}{l}\text { Education years of the father: } 0 \text { for illiteracy/near-illiteracy, } 6 \text { years for primary school, } 9 \text { years for middle } \\
\text { school, } 12 \text { years for high school, } 14 \text { years for associate’s degree, } 16 \text { years for bachelor's, } 19 \text { years for } \\
\text { master's, } 22 \text { years for PhD. }\end{array}$ \\
\hline Mother's age & The mother's age. \\
\hline $\begin{array}{l}\text { Mother's } \\
\text { education }\end{array}$ & Education years of the mother; see "Father's education." \\
\hline Late Rat & 1 if child was born in 1997 and in the last two months of the Rat year, 0 otherwise. Cutoff: 02/07/1997. \\
\hline Early Ox & 1 if child was born in 1997 and in the first two months of the Ox year, 0 otherwise. Cutoff: 02/07/1997. \\
\hline Late $\mathrm{Ox}$ & 1 if child was born in 1998 and in the last two months of the Ox year, 0 otherwise. Cutoff: 01/28/1998. \\
\hline Early Tiger & 1 if child was born in 1998 and in the first two months of the Tiger year, 0 otherwise. Cutoff: 01/28/1998. \\
\hline Late Tiger & 1 if child was born in 1999 and in the last two months of the Rat year, 0 otherwise. Cutoff: 02/16/1999. \\
\hline Early Rabbit & 1 if child was born in 1999 and in the first two months of the Ox year, 0 otherwise. Cutoff: 02/16/1999. \\
\hline Late Rabbit & 1 if child was born in 2000 and in the last two months of the Rabbit year, 0 otherwise. Cutoff: 02/05/2000. \\
\hline Early Dragon & $\begin{array}{l}1 \text { if child was born in } 2000 \text { and in the first two months of the Dragon year, } 0 \text { otherwise. Cutoff: } \\
02 / 05 / 2000 \text {. }\end{array}$ \\
\hline Late Dragon & $\begin{array}{l}1 \text { if child was born in } 2001 \text { and in the last two months of the Dragon year, } 0 \text { otherwise. Cutoff: } \\
01 / 24 / 2001 \text {. }\end{array}$ \\
\hline Early Snake & 1 if child was born in 2001 and in the first two months of the Snake year, 0 otherwise Cutoff: 01/24/2001. \\
\hline Late Snake & 1 if child was born in 2002 and in the last two months of the Snake year, 0 otherwise. Cutoff: 02/12/2002. \\
\hline Early Horse & 1 if child was born in 2002 and in the first two months of the Horse year, 0 otherwise Cutoff: 02/12/2002. \\
\hline Late Horse & 1 if child was born in 2003 and in the last two months of the Horse year, 0 otherwise Cutoff: 02/01/2003. \\
\hline Early Sheep & 1 if child was born in 2003 and in the first two months of the Sheep year, 0 otherwise. Cutoff: 02/01/2003. \\
\hline
\end{tabular}




\begin{tabular}{|c|c|}
\hline Late Sheep & $\begin{array}{l}1 \text { if child was born in } 2004 \text { and in the last two months of the Sheep year, } 0 \text { otherwise Cutoff: } \\
01 / 22 / 2004 \text {. }\end{array}$ \\
\hline Early Monkey & $\begin{array}{l}1 \text { if child was born in } 2004 \text { and in the first two months of the Monkey year, } 0 \text { otherwise. Cutoff: } \\
01 / 22 / 2004 \text {. }\end{array}$ \\
\hline Late Monkey & $\begin{array}{l}1 \text { if child was born in } 2005 \text { and in the last two months of the Monkey year, } 0 \text { otherwise. Cutoff: } \\
02 / 09 / 2005 \text {. }\end{array}$ \\
\hline Early Rooster & $\begin{array}{l}1 \text { if child was born in } 2005 \text { and in the first two months of the Rooster year, } 0 \text { otherwise. Cutoff: } \\
02 / 09 / 2005 \text {. }\end{array}$ \\
\hline Late Rooster & $\begin{array}{l}1 \text { if child was born in } 2006 \text { and in the last two months of the Rooster year, } 0 \text { otherwise. Cutoff: } \\
01 / 29 / 2006 \text {. }\end{array}$ \\
\hline Early Dog 2 & $\begin{array}{l}1 \text { if child was born in } 2006 \text { and in the first two months of the Dog year, } 0 \text { otherwise. Cutoff: } \\
01 / 29 / 2006 \text {. }\end{array}$ \\
\hline Late Dog 2 & 1 if child was born in 2007 and in the last two months of the Dog year, 0 otherwise. Cutoff: 02/18/2007. \\
\hline Early Pig 2 & 1 if child was born in 2007 and in the first two months of the Pig year, 0 otherwise. Cutoff: 02/18/2007. \\
\hline Late Rat 2 & 1 if child was born in 2009 and in the last two months of the Rat year, 0 otherwise. Cutoff: 01/26/2009. \\
\hline Early Ox 2 & 1 if child was born in 2009 and in the first two months of the Ox year, 0 otherwise. Cutoff: 01/26/2009. \\
\hline Equal & $\begin{array}{l}\text { The child's answer on “I feel that I am on an equal plane with others”. 1: strongly disagree, 2: disagree, 3: } \\
\text { neutral, 4: agree, 5: strongly agree. }\end{array}$ \\
\hline Quality & $\begin{array}{l}\text { The child's answer on “I feel that I have a number of good qualities”. 1: strongly disagree, 2: disagree, 3: } \\
\text { neutral, 4: agree, 5: strongly agree. }\end{array}$ \\
\hline Do well & $\begin{array}{l}\text { The child's answer on “I am able to do things as well as most other people”. 1: strongly disagree, 2: } \\
\text { disagree, 3: neutral, 4: agree, 5: strongly agree. }\end{array}$ \\
\hline Positive & $\begin{array}{l}\text { The child's answer on “I take a positive attitude toward myself”. 1: strongly disagree, 2: disagree, } 3 \text { : } \\
\text { neutral, 4: agree, 5: strongly agree. }\end{array}$ \\
\hline Satisfy & $\begin{array}{l}\text { The child's answer on “On the whole, I am satisfies with myself”. 1: strongly disagree, 2: disagree, 3: } \\
\text { neutral, 4: agree, 5: strongly agree. }\end{array}$ \\
\hline Respect & $\begin{array}{l}\text { The child's answer on “I wish I could have more respect for myself”. 1: strongly disagree, 2: disagree, 3: } \\
\text { neutral, 4: agree, 5: strongly agree. }\end{array}$ \\
\hline Control & $\begin{array}{l}\text { The child's answer on "I am in control of whatever happens to me”. 1: strongly disagree, 2: disagree, 3: } \\
\text { neutral, 4: agree, 5: strongly agree. }\end{array}$ \\
\hline
\end{tabular}


Panel B. Summary statistics: The sample for cognitive skills

\begin{tabular}{|c|c|c|c|c|c|}
\hline Variable & Mean & St. dev. & Min & Max & \# of obs. \\
\hline Word recognition & 21.262 & 7.510 & 0 & 34 & 1,098 \\
\hline Math test & 10.433 & 4.182 & 0 & 24 & 1,098 \\
\hline Total education cost & 2.051 & 3.384 & 0 & 15.900 & 1,098 \\
\hline Gender & 0.517 & 0.500 & 0 & 1 & 1,098 \\
\hline Urban & 0.387 & 0.487 & 0 & 1 & 1,098 \\
\hline No. of siblings & 1.818 & 0.869 & 1 & 7 & 1,098 \\
\hline Family income & 31.263 & 45.663 & 0 & 183.406 & 1,098 \\
\hline Father's age & 40.980 & 5.033 & 28 & 57 & 1,098 \\
\hline Father's education & 7.311 & 4.007 & 0 & 19 & 1,098 \\
\hline Mother's age & 39.113 & 4.745 & 26 & 51 & 1,098 \\
\hline Mother's education & 5.891 & 4.505 & 0 & 22 & 1,098 \\
\hline Late Rat & 0.049 & 0.216 & 0 & 1 & 1,098 \\
\hline Early Ox & 0.060 & 0.238 & 0 & 1 & 1,098 \\
\hline Late $\mathrm{Ox}$ & 0.060 & 0.238 & 0 & 1 & 1,098 \\
\hline Early Tiger & 0.069 & 0.254 & 0 & 1 & 1,098 \\
\hline Late Tiger & 0.084 & 0.277 & 0 & 1 & 1,098 \\
\hline Early Rabbit & 0.102 & 0.303 & 0 & 1 & 1,098 \\
\hline Late Rabbit & 0.104 & 0.305 & 0 & 1 & 1,098 \\
\hline Early Dragon & 0.098 & 0.298 & 0 & 1 & 1,098 \\
\hline Late Dragon & 0.092 & 0.289 & 0 & 1 & 1,098 \\
\hline Early Snake & 0.046 & 0.211 & 0 & 1 & 1,098 \\
\hline Late Snake & 0.032 & 0.176 & 0 & 1 & 1,098 \\
\hline Early Horse & 0.040 & 0.196 & 0 & 1 & 1,098 \\
\hline Late Horse & 0.036 & 0.185 & 0 & 1 & 1,098 \\
\hline Early Sheep & 0.036 & 0.187 & 0 & 1 & 1,098 \\
\hline Equal & 3.798 & 0.844 & 1 & 5 & 430 \\
\hline Quality & 3.760 & 0.797 & 1 & 5 & 430 \\
\hline Do well & 4.002 & 0.601 & 1 & 5 & 430 \\
\hline Positive & 3.642 & 0.995 & 1 & 5 & 430 \\
\hline Satisfy & 3.879 & 0.712 & 1 & 5 & 430 \\
\hline Respect & 4.063 & 0.737 & 1 & 5 & 430 \\
\hline Control & 3.442 & 1.027 & 1 & 5 & 430 \\
\hline
\end{tabular}


Panel C. Summary statistics: The sample for noncognitive skills

\begin{tabular}{|c|c|c|c|c|c|}
\hline Variable & Mean & St. dev. & Min & Max & \# of obs. \\
\hline Curiosity & 3.768 & 0.792 & 1 & 5 & 1,257 \\
\hline Organization & 3.545 & 0.882 & 1 & 5 & 1,257 \\
\hline Optimism & 3.941 & 0.617 & 1 & 5 & 1,257 \\
\hline Mistake tolerance & 3.557 & 0.852 & 1 & 5 & 1,257 \\
\hline Anger control & 3.352 & 0.930 & 1 & 5 & 1,257 \\
\hline Total education cost last & 1.813 & 3.517 & 0 & 15.152 & 1,257 \\
\hline Gender & 0.543 & 0.498 & 0 & 1 & 1,257 \\
\hline Urban & 0.344 & 0.475 & 0 & 1 & 1,257 \\
\hline No. of siblings & 1.808 & 0.902 & 1 & 8 & 1,257 \\
\hline Family income & 35.029 & 41.649 & 0 & 186.026 & 1,257 \\
\hline Father's age & 36.997 & 6.056 & 24 & 53 & 1,257 \\
\hline Father's education & 7.967 & 3.861 & 0 & 19 & 1,257 \\
\hline Mother's age & 35.089 & 6.107 & 20 & 50 & 1,257 \\
\hline Mother's education & 6.792 & 4.448 & 0 & 22 & 1,257 \\
\hline Late Rat & 0.033 & 0.180 & 0 & 1 & 1,257 \\
\hline Early Ox & 0.043 & 0.205 & 0 & 1 & 1,257 \\
\hline Late Tiger & 0.038 & 0.192 & 0 & 1 & 1,257 \\
\hline Early Rabbit & 0.067 & 0.250 & 0 & 1 & 1,257 \\
\hline Late Rabbit & 0.038 & 0.192 & 0 & 1 & 1,257 \\
\hline Early Dragon & 0.006 & 0.074 & 0 & 1 & 1,257 \\
\hline Late Dragon & 0.026 & 0.160 & 0 & 1 & 1,257 \\
\hline Early Snake & 0.051 & 0.220 & 0 & 1 & 1,257 \\
\hline Late Snake & 0.029 & 0.169 & 0 & 1 & 1,257 \\
\hline Early Horse & 0.032 & 0.176 & 0 & 1 & 1,257 \\
\hline Late Horse & 0.038 & 0.192 & 0 & 1 & 1,257 \\
\hline Early Sheep & 0.056 & 0.231 & 0 & 1 & 1,257 \\
\hline Late Sheep & 0.040 & 0.196 & 0 & 1 & 1,257 \\
\hline Early Monkey & 0.010 & 0.097 & 0 & 1 & 1,257 \\
\hline Late Monkey & 0.034 & 0.182 & 0 & 1 & 1,257 \\
\hline Early Rooster & 0.056 & 0.231 & 0 & 1 & 1,257 \\
\hline Late Rooster & 0.055 & 0.228 & 0 & 1 & 1,257 \\
\hline Early Dog 2 & 0.038 & 0.182 & 0 & 1 & 1,257 \\
\hline Late Dog 2 & 0.076 & 0.264 & 0 & 1 & 1,257 \\
\hline Early Pig 2 & 0.053 & 0.225 & 0 & 1 & 1,257 \\
\hline Late Rat 2 & 0.034 & 0.182 & 0 & 1 & 1,257 \\
\hline Early Ox 2 & 0.069 & 0.254 & 0 & 1 & 1,257 \\
\hline
\end{tabular}

